\title{
Crítica histórica al ensayo ¿Por qué se disipó el dinamismo industrial de Barranquilla?
}

\author{
" Historical criticism of the essay Why did the ind ustrial \\ dynamism of Barranquilla dissipate?
}

\author{
Milton Zambrano Pérez \\ Universidad del Atlántico
}

\section{Resumen}

En este estudio, el autor somete a una evaluación histórica minuciosa un ensayo que influyó decisivamente en la historiografía de Barranquilla, pues supuso un antes y un después en el desarrollo citadino: antes del descenso portuario de la ciudad y después de este, ocurrido a finales de la década de los años treinta, a manos de Buenaventura. El historiador desmonta, uno a uno, los principales supuestos y conclusiones del escrito de Meisel Roca, y plantea otra visión sobre lo ocurrido en la urbe a partir de los años treinta del siglo $\mathrm{XX}$

Palabras clave: Puerto, estancamiento, comercio exterior, industria, desarrollo urbano.

\section{Abstract}

In this study, the author submits to a thorough historical evaluation an essay that decisively influenced the historiography of the city of Barranquilla, that analyze a shift in the development of the city, that is, the period before the loss of importance of the city's port and afterwards. This happened at the end of the decade of the 1930's and was caused by the rise of the port in Buenaventura. The historian dismounts, one by one, the main assumptions and conclusions of the essay by Meisel Roca, and puts forward another vision over what happened in the city after the decade of the 1930's.

Keywords: port, stagnation, international commerce, industry, urban development.

\section{Cómo citar este artículo:}

Zambrano Pérez, M. (2019). Crítica histórica al ensayo ¿Por qué se disipó el dinamismo industrial de Barranquilla?. Revista Amauta 17(34), 63-102. DOl: http://dx.doi.org/10.15648/am.34.2019.7
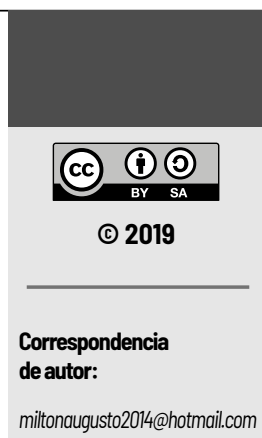

Recibido:

11/Marzo/2019

Aceptado:

17/Abril/2019

Publicado:

28/Junio/2019 


\section{Introducción}

Un estudio muy conocido del historiador Adolfo Meisel Roca (1987) lleva por título la pregunta planteada arriba. A pesar de que fue publicado a finales de los años 80 del siglo $\mathrm{XX}$, sigue siendo un trabajo con trascendencia, especialmente en el campo de los estudios de historia económica y empresarial de la ciudad. Este es uno de los principales motivos que estimulan la crítica histórica que se desarrollará en este trabajo.

Todos los enfoques que se apoyan en el escrito de Meisel Roca, terminan mostrando una situación de decadencia de la urbe, sobre todo en las décadas que siguieron a la de los años treinta, es decir, en los años 40 y 50 del siglo XX. Muchas personas siguen pensando que después de la pérdida del liderazgo portuario a manos de Buenaventura, Barranquilla entró en un marasmo económico debido a que se redujo su función portuaria, la cual había servido en el siglo XIX y a principios del siglo XX para colocarla en el primer plano a nivel nacional.

El supuesto de esas visiones catastrofistas, es el de que el peso de la función portuaria era tan decisivo que, al disminuir su importancia, automáticamente disminuiría el ritmo del crecimiento económico de la ciudad. Esta suposición se ligó a la idea del estrecho mercado regional, que no ayudaba a mantener 0 a relanzar el proceso industrializador, con lo cual se explicó otro fenómeno: el de la pérdida del dinamismo industrial de Barranquilla.

Un repaso minucioso de los datos sobre crecimiento demográfico, económico y urbanístico para las décadas de los años 40 y 50 del siglo XX permite controvertir la concepción catastrofista que se deriva de la pregunta-problema que resuelve Meisel Roca en su ensayo. En este estudio se demostrará que el ensayo de Meisel Roca carece de cifras suficientes que permitan probar de manera irrebatible lo que pretendía probar. Es más, se tratará de corroborar, con las cifras históricas de Barranquilla, que la ciudad no entró en el decaimiento socioeconómico que supone el ensayista, y que muchas de sus conclusiones sobre ese asunto, carecen de una adecuada base probatoria.

Así mismo, el escrito adolece de falta de información histórica acerca de los nexos de Barranquilla con el resto de la costa Caribe y el país, por lo cual, sus conclu- 
siones sobre la esfera de influencia de la ciudad y sobre el papel de su mercado en la continuidad de la industrialización resultan muy frágiles. Se buscará probar, que el mercado de Barranquilla trascendía a la Región Caribe y, por lo tanto, que la hipótesis del papel del mercado regional en su crecimiento industrial está mal planteada.

También se supone en el escrito de Adolfo Meisel Roca, que la pérdida del liderazgo portuario golpeó muy duro a la economía local, a tal punto que decayó relativamente con respecto a Bogotá, Medellín y Cali, contrastando las cifras de crecimiento de estas ciudades con la nuestra, pero sin mirar con detenimiento las cifras históricas de desenvolvimiento de la propia Barranquilla.

Sobre esa base, se habla de un estancamiento relativo que no sirve para demostrar si la ciudad se encontraba realmente en un estancamiento, porque el hecho de que otras ciudades hayan crecido más, no quiere decir que esta no haya crecido; el hecho de que otras ciudades hayan crecido más quiere decir solo eso, no que Barranquilla no haya crecido. Si creció o no creció, no depende de las cifras de crecimiento de Bogotá, Cali o Medellín, sino de las propias cifras históricas de Barranquilla. Esta comparación es la que sirve de base, en parte, a la teoría de la decadencia relativa, que puso de moda Meisel Roca, desde una época en que los estudios históricos acerca de Barranquilla apenas empezaban.

En este ensayo se intentará demostrar que después de la pérdida del liderazgo portuario la ciudad no se hundió en el marasmo que suponen algunos, ni perdió automáticamente sus nexos históricos con una parte del interior del país o con la Costa, a pesar de las dificultades del río Magdalena y de los problemas de comunicación derivados de la falta de carreteras y de otros medios y vías de comunicación.

Además, aquí se discutirá la hipótesis de la decadencia de la urbe en los años 40 y 50 criticando, con pruebas de la época, la tesis del estancamiento, al mostrar lo inadecuado de la metodología que sirvió de base para probarla, utilizando la comparación de algunas cifras de la ciudad con las de otras ciudades colombianas, y sin tener en cuenta las propias cifras históricas de la urbe.

Este es, pues, un ejercicio de discusión de una hipótesis muy popular que se produjo en una época en la cual los conocimientos históricos sobre Barranquilla no permitían refutarla. El conocimiento que tenemos hoy de la Costa y de la urbe, permite matizar 
y relativizar esa hipótesis, y la aparición de nuevas cifras y datos facilitan la tarea de contrastarla en sus aspectos centrales.

Este ejercicio debe ser entendido en el plano de la simple discusión histórica. Las personas no interesan aquí como tales, pues lo que se debe discutir son sus argumentos y las pruebas aportadas. Es pertinente plantear esto con claridad porque en el país y en la ciudad no existe mucho desarrollo del debate crítico sobre hipótesis 0 argumentos, y las críticas o comentarios siempre se asumen a nivel personal, como si fueran agresiones o lisonjas. La preocupación central que ilumina este trabajo consiste en hacer avanzar nuestros conocimientos históricos, agregando nuevos datos y nuevas interpretaciones a los estudios de historia económica de la urbe.

\section{Los supuestos y conclusiones del autor}

Adolfo Meisel Roca $(1993$, p.23) supone que la pérdida del liderazgo portuario de la ciudad a manos de Buenaventura trajo consigo consecuencias negativas para su desarrollo industrial y para la totalidad de su desenvolvimiento económico. Su conclusión quedó expuesta de la siguiente manera:

"Desde finales de la década del treinta la ciudad había visto deteriorar su situación económica global llevando a una pérdida del dinamismo industrial en los años cuarenta y cincuenta. El principal factor detrás de esta evolución fue la pérdida del liderazgo portuario de Barranquilla como resultado de la competencia de Buenaventura"1.

Como se observa en la cita anterior, para el ensayista la principal causa del descenso en el dinamismo industrial "fue la pérdida del liderazgo portuario de Barranquilla", enlazando el probable descenso en el comercio exterior que se movía por el río Magdalena con el decaimiento industrial de la ciudad.

Esta idea es precisada de manera más contundente en páginas posteriores: "El declive de esta última [Barranquilla] como principal puerto colombiano generó un estancamiento casi absoluto en el crecimiento industrial"(p.26).

1 Esta es la edición que seguiremos en el presente trabajo. 
Un dato clave que aporta Meisel Roca para corroborar este aserto es el siguiente:

Entre el censo industrial de 1945 y el de 1953 el empleo industrial de la ciudad solo aumentó de 14.275 a 17.382 empleados. El sector textil, que era el que absorbía el mayor número de trabajadores, tenía en 1945 3.850 empleados y creció a solo 3.894 en 1953: un estancamiento casi absoluto. (p.27)

La argumentación de Meisel Roca no se queda solo en el nivel industrial, sino que se extiende al conjunto de la ciudad. Un aspecto planteado tiene que ver con el crecimiento de la población. A este respecto escribe:

De 1938 a 1951 la población de Barranquilla creció a una tasa por debajo de las de Cali, Medellín y Bogotá (y tuvo la menor tasa de crecimiento entre las diez ciudades principales entre 1951 y 1964). (p.26)

Es decir, Meisel Roca está sugiriendo que la pérdida del liderazgo portuario no solo afectó el crecimiento industrial sino también el de la población. Sin mirar las cifras históricas de Barranquilla, por comparación con otras ciudades, deduce que la población se estancó también hacia los años 40 y 50, como un efecto de la pérdida del liderazgo portuario que había lesionado el crecimiento industrial.

El autor agrega otros factores a su explicación de por qué se produjo el declive industrial de Barranquilla. Uno fue el de las políticas centralistas y otro, el de la estrechez del mercado regional. Su planteamiento fue esbozado así:

¿Qué factores adicionales contribuyeron a la pérdida del dinamismo industrial barranquillero en la posguerra? Hay dos que destacan: [1] el tipo de encadenamiento entre este centro urbano y la economía rural de la Costa Atlántica y [2] el impacto de algunas políticas económicas seguidas por el gobierno central". (p.27)

La inexistencia de una economía monetizada (o el poco desarrollo comercial de la Región) se convirtió, para el autor, en una causa importante de la pérdida del dinamismo industrial, porque Meisel Roca establece el fenómeno del decaimiento industrial como un hecho indiscutible, a pesar de no haberlo comprobado de manera contundente. Según su lógica, el desarrollo industrial de Barranquilla no estuvo bien 
enraizado en la Región, al contrario de lo que ocurrió con Bogotá, Medellín y Cali. Esta idea la expresa así:

Las débiles interrelaciones entre el sector urbano industrial y la economía rural así como la reducida absorción de mano de obra en el sector ganadero implica que en la década de los veinte y treinta Barranquilla se desarrolló como un enclave industrial impulsado por la demanda de su propia población y de los centros urbanos aledaños como Cartagena y Santa Marta". (p.28)

Esta situación perjudicó, supuestamente, a la ciudad cuando se presentó la pérdida del liderazgo portuario. Al desaparecer o reducirse su conexión con el país, no encontró apoyo en la economía regional, pues Barranquilla se había desarrollado como un enclave industrial. El argumento fue precisado de la siguiente manera:

La naturaleza de enclave del progreso industrial barranquillero se hizo evidente cuando esta perdió su puesto como primer puerto. Su talón de Aquiles se reveló claramente cuando enfrentó la fuerte competencia de Buenaventura y no pudo depender de sus mercados regionales para continuar su expansión manufacturera y comercial". (p.29)

Otra vez el ensayista realiza una aseveración tajante sin aportar las pruebas suficientes. ¿Cómo la competencia de Buenaventura contribuyó a debilitar el crecimiento de la industria barranquillera? ¿Sí cayó drásticamente el movimiento de mercancías y personas a raíz de la pérdida del liderazgo portuario? Para lanzar expresiones tan contundentes es pertinente aportar los datos de ese movimiento, y los relacionados con el comercio exterior.

La metodología del autor es más especulativa que histórica. Él supone, que Barranquilla se desarrolló como un enclave industrial y que ese enclave tenía un contacto débil con la economía regional. Si hubiera revisado el material factual, se hubiera dado cuenta, que la idea del enclave no es tan creíble y que los nexos de Barranquilla no eran débiles sino muy fuertes con el mundo del río Magdalena, un mundo que trascendía a la Costa Caribe y hundía sus raíces en el interior del país, especialmente con el centro y el oriente de Colombia, que siguió dependiendo del río para su comercio exterior, a pesar del ascenso de Buenaventura. 
La argumentación poco sustentada de Meisel Roca se deriva de la forma como se expandió Barranquilla a partir de su función de puerto. La economía portuaria y el comercio exterior fueron decisivos en el desarrollo comercial e industrial de la ciudad, dinamizando su proceso económico. Pero de esto no se puede deducir que si cae relativamente la función portuaria, se viene al suelo el conjunto de la economía local, sin tener en cuenta la manera cómo esta se articuló al mercado que giraba alrededor del río y las cifras de la propia ciudad. El razonamiento de Meisel Roca acerca de este asunto quedó sintetizado así:

El auge industrial de Barranquilla en la década de los veinte y treinta fue el resultado de su auge comercial como primer puerto marítimo y fluvial de Colombia. Las características de enclave de este auge implicaron que el proceso de industrialización nunca tuvo raíces firmes en la economía regional costeña. Su fragilidad se hizo evidente cuando la ciudad perdió el liderazgo portuario". (pp.29-30)

Como la ciudad creció al amparo de su función portuaria, al decaer esta su efecto sería negativo, sobre todo a nivel industrial y atendiendo a que se había formado como un enclave sin mucha conexión con la economía regional. El asunto es que Meisel Roca no prueba esto con evidencia empírica, sino que lo deduce lógicamente.

A la escasez de pruebas históricas, el autor le agrega unas conclusiones derivadas del empleo del método comparativo. Al comparar las cifras de otras ciudades con las de Barranquilla, deduce que la ciudad ha caído en un bache o está estancada porque otras ciudades han crecido más. Este método lo aplica, sobre todo, al referirse al crecimiento de la población. De este modo deduce que, como la población de Cali, Medellín y Bogotá creció más, Barranquilla se estancó demográficamente.

El procedimiento es tan inadecuado, que Meisel Roca compara la tasa de crecimiento de la población de la ciudad en el año 1951 con las de Cali y las otras ciudades en el mismo año, y concluye que el crecimiento poblacional de Barranquilla se había estancado porque estaba por debajo del de las otras ciudades, cuando esa tasa de 1951, ifue la más alta de la urbe en casi todo el siglo XX!

De esta situación, es pertinente precisar que cualquier situación de la economía de la ciudad no se debe inferir solo de la simple comparación con las cifras de otra 
ciudad, sino de sus propias cifras históricas. Este es el mejor modo de saber si crece o no, si está estancada, etcétera. ¿Cómo es posible sostener que hay estancamiento en el crecimiento poblacional en Barranquilla si en el año 1951 la urbe tuvo la tasa intercensal más alta de la primera mitad del siglo xx?

La exposición que sigue de aquí en adelante, tiene como propósito refutar los principales supuestos y conclusiones contenidos en el ensayo de Adolfo Meisel Roca. Para eso, se aportarán las pruebas necesarias y se empleará la metodología propia de los historiadores, quienes construyen sus asertos y sintesis apoyados en una base de fuentes que facilitan la tarea de corroboración y crítica.

\section{Crítica histórica a los supuestos y a las conclusiones del ensayo de Adolfo Meisel Roca}

\section{La población, ¿estaba estancada en los años 40 y 50 del siglo XX?}

Una revisión de las cifras históricas de la ciudad de Barranquilla entre 1905 y 1951 permite concluir que la urbe tuvo un crecimiento poblacional en continuo ascenso, y que la pérdida del liderazgo portuario, ocurrida a finales de los años treinta del siglo $\mathrm{XX}$ a manos de Buenaventura, no afectó negativamente esa variable, como aseguró Meisel Roca.

Con base en los censos nacionales, los datos de población para Barranquilla en la primera mitad de aquel siglo fueron los siguientes:

Cuadro 1. Datos de la población de Barranquilla en la primera mitad del siglo XX

\begin{tabular}{|c|c|c|}
\hline Año & Habitantes & $\begin{array}{c}\text { Tasa de Crecimiento Anual } \\
\text { Intercensal (T.C.A.I) }\end{array}$ \\
\hline 1905 & 40.115 & 3,5 \\
\hline 1912 & 48.907 & 2,8 \\
\hline 1918 & 64.543 & 4,6 \\
\hline 1938 & 152.348 & 4,3 \\
\hline 1951 & 279.627 & 4,7 \\
\hline 1964 & 498.301 & 4,4 \\
\hline
\end{tabular}

Fuente: Adolfo Meisel Roca y otros. Series Estadídticas de Barranquilla. Barranquilla: Banco de la República, Subgerencia Técnica, p.7. 
Resalta de los datos anteriores, que la tendencia en el crecimiento poblacional no es hacia el estancamiento sino hacia un ascenso aceptable, en relación con otras ciudades de la Costa Caribe y de la República. No es posible sembrar ninguna idea en sentido contrario, pues las cifras históricas de la urbe indican que la población iba en aumento.

De los datos mostrados se puede concluir otro asunto: la mayor tasa de crecimiento anual intercensal de la primera parte del siglo XX, fue la del año 1951, año que es exhibido por Meisel Roca como catastrófico por haber sido la ciudad superada por Cali y por otras poblaciones colombianas en tasa de crecimiento poblacional.

El autor infiere un descenso poblacional en un año donde no lo hay. Y presenta ese dato como otro hecho que fue provocado por la pérdida del liderazgo portuario. $\mathrm{Ni}$ existió tal estancamiento ni esa supuesta caída fue provocada por la causa que destaca el ensayista. Todo lo contrario: el año 1951 presenta la tasa de crecimiento anual intercensal más alta de la primera mitad del siglo Xx $(4,7)$, lo cual demuestra que la población siguió creciendo a pesar de los problemas económicos que pudieron haberse derivado de la pérdida del liderazgo portuario. En este sentido, es inadecuado sembrar la idea de que la urbe también se vino al suelo en términos de crecimiento poblacional.

Es cierto que Meisel Roca escribe acerca de un estancamiento relativo, al comparar las cifras de Barranquilla con las de otras ciudades del interior. Pero, ¿sí es válido sugerir un estancamiento en la ciudad en este ítem, utilizando el método comparativo? Parece que aquí está el error cometido por el ensayista.

Al comparar la cifra de tasa de crecimiento poblacional de 1951 de la ciudad con la de otras ciudades, el autor dedujo que la población estaba estancada relativamente, y la verdad es que esa clase de ejercicio metodológico lo que hizo fue ayudarlo a construir un grueso error de apreciación, pues no se puede deducir esa clase de estancamiento con cifras que solo muestran diferencias de crecimiento entre ciudades.

El hecho de que una ciudad crezca más, no quiere decir que la otra esté estancada. La comparación solo sirve para probar que una urbe ha crecido más que otra, pero no que una no ha crecido en términos de población o que ha crecido poco. ¿Cómo 
es posible sostener la idea de que Barranquilla se estancó en cuanto a población en el año 1951 cuando ese año la ciudad presentó la más alta tasa intercensal de crecimiento poblacional de la primera mitad del siglo XX?

La conclusión del estancamiento relativo, porque Bogotá, Cali y Medellín crecieron más que ella, enmascara una realidad que sale a flote cuando uno observa las cifras históricas del crecimiento poblacional de Barranquilla: la de que la urbe crecía muy bien en términos de población, aunque a una tasa un poco menor que la de las otras ciudades mencionadas arriba. Este último hecho no significa que Barranquilla no estuviera creciendo bien; solo significa que las otras urbes estaban creciendo más en términos de población.

En consecuencia, el método comparativo no sirve aquí para demostrar que estábamos ante una catástrofe 0 ante una ralentización demográfica de la ciudad. Lo adecuado en este caso era observar las cifras históricas de la urbe para ver si la población se encontraba estancada como consecuencia de la pérdida del liderazgo portuario.

Desde principios del siglo $\mathrm{XX}$, las cifras indican una tendencia al ascenso poblacional; durante y después de los años sesenta, el ritmo de crecimiento se mantuvo por encima del $4 \%$, porcentaje que fue bueno a nivel regional, pues Barranquilla seguía creciendo más que las otras ciudades importantes del Caribe en materia de población, y que no era malo a nivel nacional, a pesar de que las tres capitales mencionadas arriba crecían más que Barranquilla. Con esta evidencia, ¿se podía deducir un estancamiento poblacional como secuela de los supuestos o reales trastornos portuarios, empleando el método comparativo?

El mayor crecimiento poblacional de otras ciudades del interior no puede servir de punto de partida para deducir un estancamiento 0 un decrecimiento de la urbe en esa materiai ese estancamiento solo puede ser derivado de las propias cifras históricas de crecimiento poblacional de Barranquilla, cuestión que no tuvo en cuenta Meisel Roca.

Como no existió en los años 40 y 50 un estancamiento en la población, la tesis que liga tal estancamiento a la pérdida del liderazgo portuario, queda sin sustento proba- 
torio. Las cifras históricas de la ciudad sirven para corroborar que no existió tal estancamiento y, por lo tanto, se oponen a una deducción que no las tuvo en cuenta.

\section{La pérdida del liderazgo portuario, ¿afectó realmente el crecimiento industrial?}

Otra conclusión que entregó Meisel Roca en su ensayo, es la de que la pérdida del liderazgo portuario lesionó el crecimiento industrial de la ciudad. Para el autor, el declive en la función portuaria trajo consigo "un estancamiento casi absoluto en el crecimiento industrial", según se citó arriba. La verdad es que el ensayista no aporta muchos datos para sustentar este aserto, y los que entrega tienen serias dificultades para servir como prueba del decrecimiento industrial provocado por el declive portuario.

¿De dónde deduce el autor, por ejemplo, el estancamiento casi absoluto del empleo industrial? De comparar las cifras del sector textil de 1945 con las de 1953. En el primer año, el empleo textil fue de 3.850 puestos de trabajo, en tanto que en el segundo este ítem solo subió a 3.894; aquí sí se observa un estancamiento casi absoluto, como lo destacó Meisel Roca.

Pero el empleo textil no era la totalidad del empleo industrial de la ciudad. Según los datos del Censo Industrial de 1945, el empleo industrial total de la urbe ascendía a 14.275 puestos de trabajo. En el Censo Industrial de 1953, el número de trabajadores empleados había subido a 17.382. Una operación matemática sencilla nos permite asegurar que la diferencia entre uno y otro censo fue de 3.107 trabajadores, es decir, hubo un aumento del empleo industrial equivalente a esta cantidad de empleos, lo cual en porcentaje está por encima del $21 \%$, una tasa de crecimiento que en el concierto nacional y regional de la época no era nada despreciable.

¿Estaba el conjunto del empleo industrial en un estancamiento casi absoluto, como lo plantea claramente Meisel Roca? Desde luego que no, porque no estamos frente a una cifra de crecimiento del $1 \%$ o menos (o ante un decrecimiento) sino ante un dato (más del $21 \%$ entre los dos censos) que no sirve para construir un aserto que revele un estancamiento casi absoluto.

El error que comete en esta oportunidad el ensayista, consistió en extrapolar inadecuadamente la cifra correspondiente al empleo del sector textil, aplicándola al 
conjunto del empleo industrial. Como el empleo en el sector textil estaba prácticamente estancado, el artificio matemático de Meisel Roca lo llevó a generalizar el dato que mostraba el estancamiento en el sector textil como si fuera el de todo el empleo industrial.

Se ha visto que tampoco en este caso hubo un estancamiento en la industria que se expresara en el nivel del empleo, como lo plantea el autor; todo lo contrario, sus propias cifras sirven para demostrar que el empleo industrial no se estancó como consecuencia de la disminución del dinamismo industrial, sino que siguió creciendo a pesar de la pérdida del liderazgo portuario, que él plantea como la principal causa en la disminución del dinamismo industrial de la ciudad en los años 40 y 50 del siglo $X X$.

Podría asegurarse que en las décadas en que el historiador destaca la pérdida del dinamismo industrial, las variables económicas relacionadas con la industria en vez de decrecer crecieron, lo cual no corrobora la correlación deductiva establecida en su escrito, pues su conclusión es la de que la economía industrial sufrió el efecto negativo de la pérdida del liderazgo portuario, y que esa causa principal lesionó a la industria y a toda la ciudad².

Por lo tanto, tampoco en este caso específico se puede aceptar el aserto contenido en el ensayo de que el empleo industrial entre 1945 y 1953 expresó un "estancamiento casi absoluto", pues esta conclusión no es cierta, partiendo de los indicios obtenidos de los censos nacionales. Por el contrario, entre los dos años de referencia, el empleo industrial de Barranquilla creció por encima del $21 \%$, lo cual sirve para demostrar que este no se hallaba estancado sino en crecimiento.

Es más, de acuerdo con las cifras del Anuario Estadístico publicado por la Contraloría General de la República en el año 1937, el número de personas ocupadas en la

2 En el nivel comercial, tampoco es posible sostener un estancamiento en la ciudad de Barranquilla en el período señalado. De acuerdo con los datos del Boletín Mensual de Estadística No 54, José Raimundo Sojo Zambrano, experto en temas económicos y a la sazón Secretario de la Cámara de Comercio, sostuvo en el año 1955 que Barranquilla estaba por esa fecha en franca expansión comercial. Ese año, el volumen de ventas del comercio se calculó en \$479.727.000, utilizando las cifras de 5.384 establecimientos censados. Las ventas per cápita de Barranquilla y el Atlántico ascendieron a \$1.120. El promedio de ventas per cápita de Barranquilla y el Atlántico estaba muy por encima del promedio nacional (que fue de $\$ 702^{\circ}$ ) y ocupó el tercer lugar a nivel nacional, solo superado por Cundinamarca y Valle del Cauca. Sojo Zambrano mostraba estos datos como una prueba de la pujanza de Barranquilla a nivel comercial. Boletín Comercial de la Cámara de Comercio de Barranquilla, Año I, Número 18 (Barranquilla: noviembre 1 de 1955), p.1. Cámara de Comercio de Barranquilla (En lo sucesivo esta fuente se citará como B.C.C.B.). 
industria de Barranquilla y el Atlántico en 1936 era de 3.700, lo cual sirve para corroborar que este nivel de empleo no se estancó sino que se expandió, si comparamos ese dato con la totalidad de las personas empleadas en la industria para los años 1945 y $1953^{3}$.

Otros datos estadísticos relacionados con la industria, tampoco acompañan la hipótesis de la pérdida del dinamismo industrial como consecuencia del declive portuario de la ciudad a manos de Buenaventura. Si se analizan con calma las cifras del número de empresas existentes en la ciudad desde finales de los años treinta en adelante podrá notarse que el crecimiento industrial no se detuvo.

En 1937, el número de establecimientos manufactureros ascendía a 126; en 1940 a 157; en 1942 a 176. Estos datos nos dan una tasa de crecimiento cercana al $25 \%$ entre cada año de referencia; y entre 1937 y 1942 de más del $30 \%$, lo cual, en términos de crecimiento, no es nada despreciable 4 . Pero aquí nos interesa resaltar, no solo el porcentaje de crecimiento del número de empresas, sino demostrar que el crecimiento industrial no estaba estancado sino en franco crecimiento.

Estos indicios sirven para corroborar que el dinamismo industrial no se vino a pique por efecto de la pérdida del liderazgo portuario, sino que el crecimiento se mantuvo a pesar del declive relativo de la función portuaria, sobre todo, en cuanto se relaciona con la exportación de sacos de café, como lo veremos un poco más adelante.

Lo más curioso del asunto es que las cifras de crecimiento industrial posteriores a 1942 confirman la idea de que el dinamismo no decreció sino que se mantuvo, contrario a lo que sostiene Meisel Roca en su artículo. Entre 1942 y 1945 se produjo un crecimiento muy notable en el número de empresas existentes, pues de 176 en el primer año se pasó a 581 en 1945, según los datos aportados por el Primer Censo Industrial de Colombia, preparado por la Contraloría General de la República y publicado en 1947.

El crecimiento no solo se produjo en cuanto al número de empresas, sino también en el capital expresado en pesos, que fue de $\$ 21.374 .923$ en 1942 y de $\$ 50.373 .417$ en

3 Adolfo Meisel Roca, y otros, Series Estadísticas..., p.11. (Cuadro 2.3: Personal ocupado en la industria de Barranquilla y el Atlántico, 1936). Las series reunidas en esta obra son útiles para refutar los supuestos y conclusiones del ensayo que se analiza.

4 Adolfo Meisel Roca, y otros, Series Estadísticas..., p.12 (Cuadro 2.4: Industria Manufacturera del Atlántico, 1937, 1940, 1942). 
1945. Es decir, el capital aplicado a las empresas industriales se duplicó en los tres años de referencia, y porcentualmente su crecimiento estuvo por encima del $100 \% 5$. ¿Se puede deducir, a partir de este dato, un estancamiento industrial como el que plantea el autor después de la pérdida del liderazgo portuario?

Desde luego que no. Es más, es pertinente poner en duda la base fáctica del ensayo, que como ya quedó consignado, es bastante irrisoria y se usa de manera inadecuada por el autor para intentar corroborar una hipótesis que, finalmente, va a ser refutada por las cifras más completas que aparecen después de la fecha en que él produce su escrito.

El surgimiento de nuevas industrias no se detuvo en los años 60 del siglo XX. A partir de 1964, emergieron nuevas empresas industriales, algunas de estas vinculadas a la Zona Franca Industrial y Comercial, que entró a operar en ese año. Aunque el crecimiento en la Zona no fue muy rápido en la primera mitad de los años 60 , sí se aceleró a partir de 1970, asociado a las confecciones y los textiles, a las manufacturas de pieles y cuero, y a las industrias metalmecánicas, entre otras ${ }^{6}$.

Un indicador importante para medir el crecimiento industrial es el del consumo de energía eléctrica por parte de las empresas industriales. Este indicador es útil para definir si hay o no crecimiento industrial, asociado a la expansión del consumo de energía eléctrica por las industrias. En 1941, la ciudad consumió 24.491 kilovatios hora; en 1950, ese consumo se había duplicado a 50.085 k.w.h.; en 1960, casi se duplicó nuevamente tal consumo, llegando hasta los 96.506 k.w.h. En los años 60, ese consumo no decreció sino que fue en aumento, hasta alcanzar en 1970 los 173.470 k.w.h $h^{7}$. Una industria y una ciudad que dependen de la energía eléctrica, y que incrementan su consumo con el paso de los años de 1940 en adelante, no pueden estar en receso ni en estancamiento sino en crecimiento ${ }^{8}$.

5 Adolfo Meisel Roca, y otros, Series Estadísticas..., p.13 (Cuadro 2.5: Número de empresas industriales de Barranquilla, capital y patrimonio -1945-. Basado en datos del Primer Censo Industrial de Colombia, Atlántico).

6 Adolfo Meisel Roca, y otros, Series Estadísticas..., p.53 (Cuadro 4.1: Número de industrias instaladas en la Zona Franca de Barranquilla por sectores de producción -1964-1985).

7 Adolfo Meisel Roca, y otros, Series Estadísticas..., pp.69-70 (Cuadro 5.4: Consumo de energía eléctrica -miles de k.w.h.).

8 Los datos obtenidos de las publicaciones de finales de los años 50 y principios de los 60, tampoco permiten concluir que la ciudad se hallaba hundida en un estancamiento económico y social. Por esa fecha, se calculaba que había en la urbe unos 1.813 establecimientos industriales con una producción representada en $\$ 284.805 .912$. Se calculó que había 14.199 puestos de trabajo industriales ocupados por hombres y 6.056 ocupados por mujeres. Entre las industrias más importantes estaban las de alimentos, bebidas, cervezas, cemento, tabaco, calzado, prendas de cuero, tostadoras de café y textiles. Algunas publicaciones de esos tiempos resaltaban que 
El incremento en el consumo de energía eléctrica por las industrias de la urbe fue destacado en los documentos de la época. En los años 40 y 50 del siglo XX, es posible constatar ese incremento como un factor del crecimiento industrial. En 1944, ese consumo fue de 17.230 .966 kilovatios/hora, en tanto que en 1954 subió a 71.599 .786 k.w.h. El incremento fue continuo a lo largo del período señalado, ubicando a Barranquilla a la cabeza de las ciudades del país en materia de consumo de energía para uso industrial. El porcentaje de aumento de este consumo en los 10 años señalados fue de $233 \%$ para Bogotá, de $188 \%$ para Medellín, de $165 \%$ para Cali, y de $315 \%$ para Barranquilla. Este tipo de consumo es un indicador del ritmo de industrialización de una ciudad. Estos datos, aparecidos en la Revista del Banco de la República (\#266 y \#329), eran presentados por los empresarios y por las autoridades como una demostración del crecimiento de la ciudad y de su pujanza económica (B.C.C.B., 1955)

el desarrollo industrial de la ciudad iba en ascenso, debido a las ventajas que ofrecía la urbe para el establecimiento de industrias. Entre esas ventajas estaban la existencia del puerto, el cual permitía que las industrias pudieran recibir sus materias primas casi en la puerta de sus fábricas, sin pagar los elevados fletes que encarecían los costos de producción de las industrias del interior. Otras ventajas favorables para el desarrollo industrial, eran las de un adecuado servicio de energía eléctrica y de un eficiente servicio de agua potable para satisfacer las necesidades industriales. También contribuía al clima de buen desarrollo industrial la abundante tierra barata, la cantidad de la fuerza laboral disponible y el acuerdo municipal $n^{\circ} 2$ de 1956, según el cual se entregaban exenciones de impuestos a las nuevas industrias que se establecieran en la urbe. A principios de los años sesenta, se habían establecido en la ciudad varias industrias nuevas, tales como Láminas del Caribe, Maderas Triplex, Fábrica de Bombillos Philips, Aluminio de Colombia Reynold-Santodomingo, Fábrica de Nylon Vanylon, Fábrica de Pinturas de W.R. Grace y Cía., entre otras. Varias de las industrias más fuertes realizaban a la sazón ambiciosos programas de ensanche. Corporación Cívica de Barranquilla. Atlántico 50 años, 1910-1950. Medellín: Interprint, 1960, p.p. 35-36. Tampoco puede asegurarse que, hacia los años 50, la actividad comercial se encontrara estancada o en una crisis. Según las cifras del Censo de Comercio de 1955, por esos tiempos funcionaban unos 5.422 establecimientos comerciales, y unos 1.037 de estos se dedicaban a la prestación de servicios como hoteles, restaurantes y teatros. Las ventas del comercio en 1954 fueron de $\$ 479.727 .000$. Las ventas per cápita estuvieron por encima del promedio nacional, que fue de $\$ 702^{\circ \circ}$, en tanto que en Barranquilla este indicador estuvo en los $\$ 1.120^{\circ \circ}$. Op. cit., p.36. El crecimiento de la urbe en los años 50 también se apreció en la expansión de la urbanización y en las obras de renovación urbana. Por esos tiempos, se construyeron nuevos edificios y muchas viviendas nuevas; surgieron nuevos barrios y se produjo la pavimentación y ampliación de calles y avenidas. En esos años se amplió la carrera Cuartel (44), la Avenida 20 de julio (carrera 43) y la Avenida de los Estudiantes (carrera 38). El Banco Central Hipotecario y el Instituto de Crédito Territorial ayudaron a desarrollar nuevos núcleos residenciales en los Altos del Prado y en urbanizaciones contiguas, y muchos barrios obreros hacia el sur de la ciudad. Para los observadores de la época, Barranquilla gozaba de una curva ascendente en la actividad edificadora. Ese auge constructor se veía reflejado, de acuerdo con los datos de la Revista del Banco de la República, en los presupuestos de las edificaciones y en la inversión en propiedad raíz. El presupuesto de las edificaciones mostró un aumento continuo de 1954 a 1959. En 1954 fue de $\$ 7.818 .000$ en tanto que en 1959 se elevó a $\$ 37.604 .000$, es decir, un incremento de un poco más del $400 \%$. En cuanto a las inversiones en propiedad raíz, en 1954 fueron de $\$ 28.923 .000$ y en 1959 se dispararon a $\$ 81.141 .000$, un crecimiento notable para esos tiempos. El crecimiento también se expresó en el aumento de la actividad de las plantas de la Compañía colombiana de Electricidad. En 1927, tales plantas generaban unos 4.478 kilovatios, en tanto que en 1959 su generación ascendió a los 54.900 kilovatios. El número de consumidores se elevó de 10.518 en 1927 a 47.063 a finales de 1959. Esto tenía que ver con el crecimiento de la población y de la economía. En 1927 la Compañía atendía a unos 108.000 habitantes, en tanto que en 1959 la cantidad de habitantes se elevó a unos 400.000. Op. cit., p. 61. 


\section{Efectos del ascenso del comercio exterior por Buenaventura sobre el puerto de Barranquilla}

Otro asunto importante que se deriva de los supuestos del escrito que analizamos, tiene que ver con el impacto del ascenso portuario de Buenaventura sobre el comercio exterior que circulaba por Barranquilla. Meisel Roca siembra la idea de que el paso de Buenaventura al primer lugar entre los puertos colombianos provocó casi una catástrofe en el comercio exterior de Barranquilla, que luego se proyectó a todo el funcionamiento de la ciudad, generando estancamiento, pérdida del dinamismo industrial, etcétera.

Las cifras de comercio exterior de la ciudad entre 1936 (año en que se inaugura el Terminal Marítimo y Fluvial) y 1960, no sirven para demostrar que la función portuaria de la urbe colapsó como consecuencia de que las exportaciones e importaciones utilizaran el puerto de Buenaventura en una proporción cada vez más notoria. Como lo veremos enseguida, el crecimiento en el comercio exterior por Barranquilla no se estancó en los años 40 y 50, al contrario de lo sugerido por Meisel Roca en su estudio.

Si analizamos las cifras históricas de comercio exterior de la ciudad entre 1936 y 1960, sale a relucir que tuvieron un crecimiento casi continuo, y que la pérdida del liderazgo portuario no representó una catástrofe para ese comercio, como supone Meisel Roca sin haber estudiado tales cifras. Los datos del comercio exterior por año, y en miles de pesos, son los siguientes:

Cuadro 2. Importaciones y exportaciones por las principales aduanas

\begin{tabular}{|c|c|}
\hline Año & Comercio exterior en miles de pesos \\
\hline 1936 & $\$ 89.174$ \\
\hline 1937 & $\$ 115.672$ \\
\hline 1938 & $\$ 103.380$ \\
\hline 1939 & $\$ 111.568$ \\
\hline 1940 & $\$ 85.238$ \\
\hline 1941 & $\$ 106.704$ \\
\hline 1942 & $\$ 89.628$ \\
\hline 1943 & $\$ 114.631$ \\
\hline 1944 & $\$ 120.016$ \\
\hline
\end{tabular}




\begin{tabular}{|c|r|}
\hline Año & Comercio exterior en miles de pesos \\
\hline 1945 & $\$ 187.536$ \\
\hline 1946 & $\$ 259.476$ \\
\hline 1947 & $\$ 369.792$ \\
\hline 1948 & $\$ 342.365$ \\
\hline 1949 & $\$ 311.881$ \\
\hline 1950 & $\$ 524.624$ \\
\hline 1951 & $\$ 660.106$ \\
\hline 1952 & $\$ 651.327$ \\
\hline 1953 & $\$ 900.286$ \\
\hline 1954 & $\$ 865.326$ \\
\hline 1955 & $\$ 648.201$ \\
\hline 1956 & $\$ 627.338$ \\
\hline 1957 & $\$ 960.490$ \\
\hline 1958 & $\$ 1.144 .056$ \\
\hline 1959 & $\$ 932.764$ \\
\hline 1960 & $\$ 1.019 .340$ \\
\hline
\end{tabular}

Fuente: Adolfo Meisel Roca, y otros. Series Estadísticas de Barranquilla (Barranquilla: Banco de la República, Subgerencia Técnica, 1991), pp.24-26.

Estos son los datos de las décadas en que Meisel Roca destaca el hecho de la pérdida del liderazgo portuario a manos de Buenaventura y en las cuales da a entender que esa pérdida provoca un estancamiento en el comercio exterior que afecta al resto de la economía barranquillera, y hasta al crecimiento poblacional. A partir del año 1964, las cifras de comercio exterior de la ciudad se disparan aún más hacia arriba y esto coincide con la aceleración del uso de algunas carreteras, especialmente la que comunica a la urbe con el interior del país, a través de Medellín.

Los datos históricos de comercio exterior muestran claramente una tendencia al alza, con breves oscilaciones que no están relacionadas con la pérdida del liderazgo portuario. Por ejemplo, el declive relativo entre los años 1942 y 1944 está directamente relacionado con la fractura del comercio mundial ocasionado por la gran guerra de esos años. Obsérvese cómo a partir de 1945 empieza una lenta pero consistente recuperación que desemboca en la alta cota del año 1957, cuando el monto del comercio exterior prácticamente se duplica, si lo comparamos con el del año 1953. 
Estos son los años preferidos por Meisel Roca para escribir sobre el estancamiento económico de la urbe asociado a su decaimiento portuario, lo cual tuvo como punto de partida un declive notable de su comercio exterior, de acuerdo con la hipótesis planteada por el autor ${ }^{9}$.

Como se demostró con las cifras históricas del comercio exterior de la ciudad, tal descenso en ese comercio es otro invento deductivo que es imposible probar estadísticamente. Y si no es posible probar que el efecto de la pérdida del liderazgo portuario provocó una catástrofe que lesionó la economía citadina, no se puede seguir sosteniendo que la ciudad entró en una gran decadencia en los años 40 y 50 del siglo XX, como consecuencia de esa pérdida que tantos problemas le trajo al crecimiento económico de la urbe, de acuerdo con las deducciones de Meisel Roca ${ }^{10}$.

Según las cifras de la época, todavía en el año 1938 Barranquilla superaba a Buenaventura en el monto del comercio exterior expresado en pesos. Veamos: Importaciones por Barranquilla: \$75.399; exportaciones: \$27.981; total: \$103.380. Importaciones por Buenaventura: \$38.248; exportaciones: \$46.192; total: \$84.440. En 1945, la situación entre los dos puertos seguía siendo equilibrada en cuanto al monto total del comercio exterior. Barranquilla: Importaciones: \$117.181; exportaciones: \$70.355; total: \$187.536. Buenaventura: Importaciones: \$96.968; exportaciones: \$91.972; total: \$188.940. Teniendo en cuenta estos indicios históricos, es posible asegurar

9 Cabe anotar que en el primer semestre de 1958 (un año clave, en el supuesto decaimiento de la urbe) el Terminal Marítimo y Fluvial de Barranquilla ocupó el primer lugar entre todos los puertos colombianos en el rubro de las importaciones para la industria y el comercio colombianos. De enero a junio de ese año, la carga importada por Barranquilla ascendió a 194.971 toneladas; por Buenaventura, a 178.958 toneladas; por Cartagena, a 83.765 toneladas, y por Santa Marta, a 13.203 toneladas. Agregando la carga ingresada en el mes de julio de ese año, las cifras fueron: Barranquilla: 226.251 toneladas; Buenaventura: 198.338 toneladas; Cartagena: 92.376 toneladas, y Santa Marta: 14.207 toneladas. B.C.C.B., Año IV, Número 125. (Barranquilla: septiembre 15 de 1958), Cámara de Comercio de Barranquilla.

10 La idea de la decadencia o del estancamiento en los años 40 y 50 ha rodado desde hace rato en la ciudad dando pie a interpretaciones que sostienen que la urbe se vino prácticamente al suelo en ese período. Como estamos analizándolo, eso no se puede establecer con los datos aportados por las fuentes, pues el cuadro que resulta después del análisis de las cifras es completamente diferente al que mostró Meisel Roca. Por esos años estuvieron en funcionamiento las Empresas Públicas municipales, una entidad que se convirtió en modelo nacional y que operó muy bien hasta poco antes de que se le suprimiera la protección contra la politiquería que operó en la época del fideicomiso con los banqueros norteamericanos. Esas Empresas funcionaban mediante un sistema descentralizado que les garantizaba autonomía administrativa con respecto al Concejo y a la Alcaldía, y el manejo independiente de su propio presupuesto. Como lo resaltaban los observadores de la época, ese modelo permitió que dentro de las Empresas primaran los criterios técnicos, la absoluta independencia con respecto a los vaivenes de la política y el que los planes se ejecutaran de manera eficiente, pues se contaba con buen movimiento de los recursos propios. En varios sitios de la urbe se notó la mano de las Empresas en la pavimentación de calles, en el mejoramiento de la distribución de agua potable, etcétera. La actividad de las Empresas Públicas Municipales no coincidió con una etapa de estancamiento económico y urbano sino todo lo contrario. B.C.C.B., Año V, Número 155. (Barranquilla: mayo 4 de 1959), pp.1-2, Cámara de Comercio de Barranquilla. 
que el comercio exterior por Barranquilla no cayó en picada como consecuencia del ascenso de Buenaventura.

En 1950, Barranquilla superaba a Buenaventura en el rubro de las importaciones, pero era superada por esta en cuanto al monto de las exportaciones, aunque el comercio exterior en general por los dos puertos mostraba una ventaja para la segunda, sin tomar una distancia considerable con respecto a la primera. Las cifras son las siguientes: Barranquilla: Importaciones: \$338.286; exportaciones: \$186.338; total: \$524.624. Buenaventura: Importaciones: \$245.156; exportaciones: \$397.957; total: $\$ 643.113$. De estos datos tampoco es posible deducir una caída escandalosa del comercio exterior por Barranquilla como consecuencia del ascenso de Buenaventura $y$, en consecuencia, un efecto dominó negativo sobre el crecimiento industrial y sobre el desarrollo general de la ciudad.

Las cifras del comercio exterior de Barranquilla siguieron en aumento desde 1952 hasta el año 1960. A finales de los años cincuenta se conoció un repunte sin precedentes tanto en volumen de carga importada y exportada como en términos monetarios. Esos datos son fundamentales para desvirtuar la idea del colapso del comercio exterior por la ciudad, como un punto de partida para explicar la supuesta pérdida del dinamismo industrial y el declive económico y poblacional de la urbe.

Es cierto que en este período también ocurre un repunte del comercio exterior por Buenaventura, especialmente en el rubro de las exportaciones $y$, sobre todo, en la cantidad de sacos de café exportados por ese puerto. Pero de este hecho solo es posible deducir que el comercio exterior creció mucho más por Buenaventura que por Barranquilla. Las cifras históricas no dan para concluir que la ciudad había caído en un profundo bache, en un estancamiento en su función portuaria principal, como consecuencia de haber perdido el liderazgo portuario con Buenaventura. La conclusión de que la pérdida del liderazgo portuario afectó gravemente el comercio exterior por Barranquilla no se puede corroborar con ninguna prueba, si nos atenemos a las cifras históricas de ese comercio para el caso de Barranquilla en los años 40 y 50 del siglo XX.

El repunte de Buenaventura en el comercio exterior a partir del año 1952 no representa un declive del comercio exterior por Barranquilla que, como ya vimos, creció hasta alcanzar sus cotas más altas a finales de la década. Aquí el método comparativo 
parece haber realizado otra pilatuna, pues el hecho de que el comercio exterior de Buenaventura creciera más que el de Barranquilla, no significa que el de esta última ciudad no creciera o estuviese estancado o entrara en una profunda crisis; lo que las cifras de la época indican es que el comercio exterior por Barranquilla creció menos que el de Buenaventura, pero no que estuviera estancado o que se hubiera venido al suelo.

Lo único que sirve para aclarar si el comercio exterior por Barranquilla colapsó como consecuencia de la pérdida del liderazgo portuario a manos de Buenaventura, es la revisión minuciosa de las cifras históricas de su comercio exterior, pero no la comparación con las cifras de ese comercio por Buenaventura.

Dicha comparación no permitió aclarar si había ocurrido un colapso en el comercio exterior barranquillero como consecuencia de la pérdida del liderazgo portuario, porque sus referentes eran muy fragmentarios y no entregaban una idea clara de la evolución histórica de ese comercio.

El análisis de las cifras históricas de la ciudad muestra con mucha claridad que, al contrario de lo que dedujo Meisel Roca, el crecimiento del comercio exterior por Barranquilla en los años 40 y 50 del siglo XX fue casi continuo y que ese crecimiento, que se aceleró en las cercanías de los años 60 , no sufrió, en volumen y valor en pesos, un daño notable, a pesar del ascenso de Buenaventura.

De donde se colige que si no cayó el comercio exterior, tampoco se vino a pique el crecimiento industrial ni se estancó la ciudad y su población", siguiendo el camino contrario de la deducción de Adolfo Meisel Roca, para quien la pérdida del liderazgo portuario a manos de Buenaventura fue la causa principal que originó el supuesto estancamiento en todos los órdenes de la urbe. El estudio de las cifras históricas del comercio exterior de la ciudad, permite desmontar el mito de que se precipitó en el

11 Un índice de que el desarrollo de la urbe iba en aumento tiene que ver con la cantidad de vehículos que transitaban por sus calles. De 1949 a 1954, el número de estos vehículos se incrementó en un $40 \%$ : de 6.107 en 1949 pasó a 9.254 en 1954. Este aumento se produjo sobre todo en medios de transporte motorizados. En este último año, los automóviles de 5 puestos que entraron a la plaza fueron 4.818, los camiones de hasta 2 toneladas llegaron a los 1.418 y los autobuses de diversa capacidad sobrepasaron las 500 unidades. B.C.C.B., Año I, Número 7. (Barranquilla: mayo 15 de 1955), Cámara de Comercio de Barranquilla. 
estancamiento como resultado de una pérdida del liderazgo portuario que la sumió en un gran marasmo en los años 40 y 50 del siglo $X X^{12}$.

De hecho, desde 1938 y hasta los años 70 del siglo XX, Barranquilla superó en volumen y precio del comercio exterior a los demás puertos colombianos distintos a Buenaventura, y superó a este último puerto en varios años en cuanto al monto de las importaciones. En 1960, por ejemplo, las importaciones por Barranquilla subieron a \$880.960; en 1965 fueron de \$1.260.459 y en 1970 llegaron a los \$5.168.591, cifra que estuvo por encima de las importaciones por Buenaventura ese año (que llegaron a los \$3.975.805). A partir de 1970, las cifras revelan un crecimiento sostenido del comercio exterior por Barranquilla, lo cual siembra otras dudas sobre el supuesto efecto de la pérdida del liderazgo portuario ${ }^{13}$.

Lo que sí se desplomó por Barranquilla fue la exportación de sacos de café, la cual empezó a declinar dramáticamente desde los años 50, hasta reducirse a su mínima expresión a principios de los años 6014. Tal vez Meisel Roca se apoyó en este dato para hacer su deducción, olvidando que por la urbe aún transitaban en los años 40 y 50 muchos de los productos exportables distintos al café que tenían al río Magdalena como eje de su operación, y que por motivos geográficos o infraestructurales no utilizaban el puerto de Buenaventura ni ningún otro puerto colombiano.

Mientras en 1927, Barranquilla era el principal puerto exportador de café (con 1.182.500 sacos de 60 kilos), en 1938 solo exportó 1.120 .600 sacos, y ya era superada por Buenaventura (2.115.600 sacos). En 1950 aún mantenía la segunda posición entre los puertos exportadores de café (con 1.329.600 sacos), superada solo por Buena-

12 Este mito no solo puede ser desmontado mediante el análisis de las cifras, sino también acudiendo a lo que pensaban los protagonistas de aquellos tiempos. La percepción que tenía el empresariado hacia el año 1959, por ejemplo, era la de que Barranquilla tenía una economía industrial en expansión. Se veía con optimismo el desarrollo de las carreteras que conectaban a la ciudad con el occidente y con el oriente del país. También se destacaba el nuevo rol del Ferrocarril del Atlántico en la dinamización del comercio. De acuerdo con los datos del censo industrial de 1953, los empresarios anotaban que la urbe no había dejado de crecer en materia industrial y que la Zona Franca Industrial y Comercial (creada legalmente mediante la Ley 105 de 1958) sería el espaldarazo definitivo en la industrialización de la urbe. En un informe de la Corporación Cívica, bajo el título "Barranquilla, Ciudad Industrial en Expansión", se resaltaba también el crecimiento y la transformación urbana derivados de la pavimentación y construcción de nuevas vías y del desarrollo de nuevas urbanizaciones construidas por el Banco Central Hipotecario, el Instituto de Crédito Territorial y los empresarios independientes. Boletín Semanal de la Cámara de Comercio de Barranquilla, Año V, Número 168. (Barranquilla: agosto 3 de 1959), Cámara de Comercio de Barranquilla.

13 Adolfo Meisel Roca, y otros, Series Estadísticas..., 24-26 (Cuadro 3.1: Importaciones y exportaciones por las principales aduanas -en miles de pesos).

14 Adolfo Meisel Roca, y otros, Series Estadísticas..., 35 (Gráfico 3: Exportaciones por Barranquilla y total nacional -1927-1988). 
ventura (2.881.100 sacos). Pero a partir del año 1955, empieza su gran declive como puerto exportador de café, exportando ese año menos de la mitad de lo exportado en 1950 (508.200 sacos) y descolgándose en las décadas siguientes hacia cifras insignificantes en la exportación del grano ${ }^{15}$.

¿Es posible deducir una catástrofe para el puerto como consecuencia de la caída de la exportación de café? Desde luego que no. Empezando porque el comercio exterior de Barranquilla ya integraba un alto componente de importaciones y exportaciones ligadas a la economía de la ciudad, y ese rubro siguió creciendo a pesar de la pérdida del liderazgo portuario y de la reducción de las exportaciones de café. Y terminando, con el hecho de que el comercio exterior por Barranquilla no se derrumbó en los años 40 y 50 porque su puerto seguía integrando varias zonas del país al mercado mundial a través del río Magdalena.

El descenso del comercio exterior que circulaba por el río no fue tan rápido, como a veces se supone, sino relativamente lento. La pérdida del liderazgo portuario no afectó inmediatamente a ese comercio, pues las funciones del río no desaparecieron de un solo golpe en esa materia, sino que se transformaron y fueron languideciendo poco a poco, atacadas por otros medios de transporte y otras vías de comunicación, como las carreteras y el Ferrocarril del Atlántico.

El movimiento marítimo y fluvial por el puerto de Barranquilla siguió su curso, enfrentando toda suerte de dificultades pero sobreponiéndose y confrontando los problemas, de la mano de los intereses de su empresariado y de las autoridades locales. Las cifras en cuanto al monto de la carga no indican una catástrofe y ni siquiera un estancamiento, como resultado de que Buenaventura se elevara al primer lugar entre los puertos colombianos.

La carga embarcada en 1940 fue de 88.328 toneladas; en 1945 este rubro subió a 118.858 toneladas, y en 1950 llegó a 119.235 toneladas. En 1953, la carga embarcada ascendió a 142.751 toneladas y luego, en 1955, descendió a las 70.497 toneladas. Sin embargo, a partir de 1957 hubo un repunte ( 98.700 toneladas), que fue coronado

15 Adolfo Meisel Roca, y otros, Series Estadísticas..., 36 (Cuadro 3.7: Exportaciones colombianas de café por puerto de embarque -miles de sacos de 60 kilos). 
con un ascenso muy notable en 1959 cuando fueron exportadas 247.400 toneladas. Entre 1940 y 1960, lo que caracterizó a las exportaciones fue su inestabilidad, aunque nunca cayeron a niveles catastróficos.

La carga desembarcada (importaciones) fue mucho más estable y con tendencia al alza. En 1940 esa carga importada fue de 146.254 toneladas. En 1945 llegó a las 206.543 toneladas, en el año 1950 se trepó a las 456.546 toneladas, es decir, se duplicó con respecto a la carga de 1945. En el año 1954 fue alcanzado el tope más alto en toda la década, cuando la carga de importación se elevó a las 721.873 toneladas $^{16}$. Las cifras de la carga importada en los años 40 y 50 del siglo XX, tampoco permiten sacar la conclusión de que el comercio exterior por Barranquilla estaba estancado. Todo lo contrario: gozaba de un crecimiento aceptable.

Las cifras históricas de comercio exterior de la ciudad en los años 40 y 50 del siglo $X X$, no permiten concluir que la urbe entró en pánico como consecuencia de la pérdida del liderazgo portuario a manos de Buenaventura. Como quedó consignado, el descenso relativo a nivel portuario no fue brusco sino lento, y donde más se vio ese descenso fue en las exportaciones de café, sobre todo hacia los años 50 . Barranquilla mantuvo cierto equilibrio en las importaciones con Buenaventura y la ventaja de esta se dio primero en las exportaciones, sobre todo de café.

Sin embargo, la pérdida del liderazgo portuario no representó la debacle para el comercio exterior por Barranquilla ni tampoco que ese comercio se estancara en los años 40 y 50, produciendo los efectos negativos sobre el crecimiento industrial y poblacional que dedujo Adolfo Meisel Roca en su ensayo. ¿Por qué Barranquilla siguió creciendo, a pesar de las dificultades relativas que presentó su función portuaria?

16 Adolfo Meisel Roca, y otros, Series Estadísticas..., 39 (Cuadro 3.9: Movimiento marítimo y fluvial de Barranquilla -1940-1959). De acuerdo con los documentos originales de la época, Barranquilla aventajó en cuanto a porcentaje de importación a todos los puertos colombianos a principios de los años 50 . El volumen de importaciones ubicó arriba a la ciudad con un $43 \%$ del total nacional, seguida de cerca por Buenaventura con un 42 $\%$; después estuvo Cartagena, con el $13 \%$ y al final de la tabla se ubicó Santa Marta, con el $2 \%$. Sobre un gran total de importaciones de 1950 a 1954 que ascendió a 6.314.037.890 kilos, Barranquilla obtuvo un porcentaje de movimiento que le permitió superar al de los otros puertos colombianos. En 1950 importó 403.031 .983 kilos, en tanto que Buenaventura recibió solo 381.161.342 kilos; en 1953, la ciudad recibió 685.696.711 kilos y Buenaventura 611.677.510 kilos. Ya en 1954, Buenaventura sí superó a Barranquilla con 802.857.000 kilos contra 747.319.00 kilos. B.C.C.B., Año I, Número 6. (Barranquilla: mayo 10 de 1955), p.3, Cámara de Comercio de Barranquilla. 


\section{Barranquilla: ¿un enclave industrial desconectado de la economía del río Magdalena?}

Ya vimos que fue un error deducir un decaimiento industrial a partir de la pérdida del liderazgo portuario. En realidad, la pérdida del liderazgo portuario no representó una catástrofe ni para el puerto ni para la economía de la ciudad, como se deduce de los datos estadísticos.

Otro error en el enfoque de Meisel Roca, consistió en mantener la tesis del decaimiento industrial, derivado de la pérdida del liderazgo portuario, ahora atado a un mercado regional que no le ayudó a mantener el ritmo de crecimiento industrial de las primeras décadas del siglo XX. Según los datos, para los años 40 y 50 del siglo $X X$, no se puede sostener que la economía barranquillera estaba estancada. Por tal razón, tampoco es posible expresar que ese decaimiento industrial inexistente se mantuvo porque el mercado regional poco desarrollado, no permitió que la ciudad siguiera creciendo industrialmente al mismo ritmo de las décadas anteriores.

El mercado de Barranquilla y las relaciones económicas que la ciudad construyó, trascienden la idea del mercado regional que Meisel Roca supuso en su ensayo. El autor parece sostener la idea de que el mercado del cual se nutría (o que abastecía) Barranquilla, estaba solo en sus alrededores o en el hinterland, en los departamentos de Magdalena y Bolívar. Esto es parcialmente cierto para las zonas ribereñas que pertenecen a esos departamentos (y para el hinterland conectado con esas zonas), pero no es cierto para el resto de territorios integrados a la economía de Barranquilla a través del río Magdalena.

Por la ruta del río, Barranquilla se integró muy bien con los pueblos o ciudades de las riberas y con las regiones o subregiones de otros departamentos que hicieron parte del sistema de transportes que se conectó al comercio exterior, sobre todo desde la segunda mitad del siglo XIX'7.

La ciudad no estaba bien conectada con Santa Marta y Cartagena, si dejamos de lado la vía marítima, que no era muy apta para las embarcaciones a vapor que

17 Sobre los nexos construidos alrededor del río ver: Aníbal Noguera Mendoza, Crónica grande del río de la Magdalena, Tomos I y II (Bogotá: Ediciones Sol y Luna, 1980). Descripciones sobre el viaje del interior y a través del río hasta Barranquilla desde el siglo XIX se hicieron por parte de algunos viajeros. Véase Salvador Camacho Roldan, Notas de viaje: Colombia y Estados Unidos de América, Tomo I (Bogotá: Talleres Gráficos del Banco de la República, 1973). 
surcaban el río. El transporte de mercancías y personas a través de los caños y de la Ciénaga Grande nunca fue fácil; pero a pesar de las dificultades, existió un intercambio bastante regular de mercancías y pasajeros por lo menos hasta la población de Ciénaga, desde donde se podía seguir avanzando hasta Santa Marta por caminos nada ventajosos (Nichols, 1973).

La conexión con Cartagena era más simple, subiendo el Magdalena hasta Calamar y entrando luego al Canal del Dique para empalmar con la Bahía de Cartagena, en un trayecto que lucía muy largo para aquellos tiempos, a pesar de la cercanía geográfica de las dos ciudades, el cual siempre dependió de las condiciones de navegabilidad del Canal y del propio río Magdalena.

De todas maneras, el río fue el principal medio para que la ciudad tejiera una conexión que le permitió irrigar los bienes importados y los que producía en sus industrias, así como recibir bienes primarios que servían como materias primas o bienes intermedios para sus empresas industriales ${ }^{18}$.

Varias de las casas de comercio que cumplían esta función y que tenían por sede a Barranquilla, también abrieron sucursales en los pueblos y ciudades ribereñas o en las poblaciones conectadas con Barranquilla por el río y por el comercio exterior. Tales sucursales no solo estaban en Calamar, Magangué ${ }^{19}$ o Mompox sino en Puerto Berrio, Barrancabermeja u Honda, entre otras.

A partir de los pueblos o puertos sobre el Magdalena, el tejido en el cual Barranquilla cumplía un rol principalísimo se expandía hacia el interior de varios departamentos que no pertenecían a lo que hoy llamamos Costa Caribe, como Antioquia, Boyacá, Cundinamarca, Tolima o Santander. La conexión de la ciudad con esas zonas era

18 Hacia los años 30 y 40 del siglo XX, los puertos de más movimiento y contacto con Barranquilla eran Caracolí, La Dorada, Puerto Liévano (después llamado Puerto Salgar), Puerto Berrio, Barrancabermeja, Puerto Wilches, Gamarra, El Banco, Magangué, Calamar, Ciénaga y Cartagena. De Castro Palacio, Arturo. Boletín Municipal de Estadística, Vol. III, No 19. Barranquilla: Archivo Histórico del Atlántico, p.26. Eduardo Posada Carbó, Una invitación a la historia de Barranquilla (Bogotá: Cámara de comercio de Barranquilla-CEREC, 1984), en varios lugares.

19 Magangué fue un importante centro de acopio de ganado que se enviaba a la exportación, siguiendo la ruta de Barranquilla. El transporte de ganado era importante a través del río, y Magangué se había convertido en el puerto más importante para distribuir ganado hacia el interior o hacia Barranquilla a través del Magdalena. Se calcula que entre 1940 y 1944 se trasportaron cada año por el río unas 107.000 cabezas de ganado. Eduardo Posada Carbó, El Caribe colombiano, una historia regional (1870-1950)(Bogotá: Banco de la República-El Ancora Editores, 1988), 270. Sobre la presencia en otros puertos y ciudades de casas comerciales con sede en Barranquilla, véase Milton Zambrano Pérez, El desarrollo del empresariado en Barranquilla, 1880-1945 (Barranquilla: Fondo de Publicaciones de la Universidad del Atlántico, 1998). 
más sólida de lo que a veces se supone, pues se olvida que en materia de puerto para el comercio exterior Barranquilla estuvo más integrada con tales regiones que con muchas otras de lo que hoy llamamos el Caribe colombiano.

En consecuencia, el mercado de Barranquilla para sus productos industriales (o para las importaciones) no era solo el de la Costa Caribe sino aquel que giraba alrededor del río Magdalena, el cual fue mucho más que un simple mercado regional estrecho y poco monetizado. Es fácil comprender que la falta de comunicación alternativa a la que ofrecía el río, conspiraba contra el desarrollo de un mercado interno regional y favorecía el desarrollo de un mercado alrededor del Magdalena, que trascendió las supuestas fronteras regionales.

Este hecho económico es muy importante para explicar la continuidad del desenvolvimiento industrial de la urbe, y la continuación de su papel en el comercio exterior colombiano, a pesar de la pérdida del liderazgo portuario a manos de Buenaventura. Esa pérdida no representó un decaimiento catastrófico de su comercio exterior, como ya fue analizado, ni tampoco afectó dramáticamente el desarrollo de su industria, que no se estancó como sugiere Meisel Roca, sino que continúo creciendo en los años 40 y 50 del siglo XX.

La conexión de Barranquilla con un mercado que superaba el supuesto mercado regional de Meisel Roca, desmonta otra de las conclusiones de este autor: la de que el dinamismo industrial de la ciudad decayó porque no contó con un mercado que respaldara su crecimiento industrial, debido a su poco desarrollo 0 a la escasez de demanda efectiva para los productos industriales de la ciudad. Y, por el contrario, la existencia de un mercado tejido alrededor del río Magdalena y con un alcance que estaba más allá de los departamentos de la Costa, sirve para explicar el mantenimiento del desarrollo industrial de Barranquilla, el cual también estuvo ligado a las exportaciones y a su propia demanda interna.

La pérdida del liderazgo portuario a manos de Buenaventura, no trajo consigo un desastre para la industria Barranquillera porque su mercado estaba más allá de los departamentos de la Costa y porque, ya por esos tiempos, la ciudad exportaba bienes industriales al mercado mundial, especialmente a varios países de la cuenca del Caribe. La demanda de los pueblos ribereños de la Costa Caribe, de las zonas interiores que se conectaban con esos puertos, más la demanda de los puertos del 
interior conectados con regiones o ciudades de los departamentos no costeños, sirve para explicar, en parte, la continuidad del crecimiento industrial de Barranquilla, a pesar de las dificultades del río y de la urbe como puerto. A este aspecto se liga la demanda existente en el mercado exterior y en la propia ciudad, que fue creciendo con el paso del tiempo.

En cuanto al comercio exterior, hay que anotar que el tejido de transportes construido alrededor del río Magdalena no decayó enseguida, como consecuencia del ascenso portuario de Buenaventura. De hecho, el transporte de carga y pasajeros no disminuyó de inmediato, sino mucho después de la pérdida del liderazgo portuario, y no tanto por este, sino por el abandono paulatino del río como medio de transporte, al ser desplazado por el Ferrocarril del Atlántico y por las carreteras, los camiones y los buses, sobre todo desde los años 60 en adelante ${ }^{20}$.

Según el Informe Lebret (1958), el tráfico de carga por el Magdalena en el año 1954 fue de 1.750 .000 toneladas, cifra nada despreciable si la comparamos con otras anteriores y posteriores. En el año 1953, el número de pasajeros embarcados fue de 226.412; en 1954 ese número subió a 283.355. Por esos tiempos, los puertos más importantes seguían siendo La Dorada, Puerto Salgar, Puerto Berrío, Honda, Barrancabermeja y Puerto Wilches. Estos puertos eran también, junto a otros menores, puntos de entrada y salida de regiones interconectadas por el río Magdalena. Barranquilla seguía siendo en los años 50 la capital fluvial del país (Poveda Ramos, 1998; Gómez-Picón, 1983).

20 Hacia 1960, la carretera Troncal Occidental que comunica a Barranquilla con Medellín estaba ya funcionando para el tráfico de camiones. Hacia 1961, se terminó la carretera Calamar-Carreto, que acortaría la distancia a Medellín en unos 80 kilómetros. Esta parte de la carretera Troncal Occidental permitió a la industria y al comercio de la ciudad vincularse mejor con los mercados del occidente y estrechar su relación con las ricas regiones ganaderas de Bolívar y Córdoba. La carretera Troncal Oriental, que comunicó a la urbe con el oriente y con la capital del país, no había sido terminada en 1960, pero se trabajaba a buen ritmo en varios frentes, como las variantes Las Pavas-El Paso-Rinconhondo y La Mata-Aguachica; en 1958 ya se había dado al servicio el tramo Aguachica-Bucaramanga. En 1960 estaba en construcción la carretera Barranquilla-Ciénaga, que conectaría a la ciudad con las zonas agrícolas y ganaderas del Magdalena y La Guajira. Todas estas nuevas carreteras ayudarían a acelerar el crecimiento de la industria y el comercio de Barranquilla en las décadas por venir. Corporación Cívica de Barranquilla. Atlántico 50 años, 1910-1960, op. cit. pp.34-35. De acuerdo con las fuentes de la época, hacia el año 1955 empezó a aumentar el comercio por carretera entre la ciudad y otros lugares del país diferentes a la Costa. La apertura de la carretera a Medellín ayudó a avivar el intercambio comercial entre esta ciudad y Barranquilla. En enero de 1955, por ejemplo, la carga movilizada por esa ruta fue de 2.598 toneladas. La carga movida hacia o desde los departamentos vecinos también experimentó un aumento, transportándose en enero de ese año 8.662 toneladas. B.C.C.B., Año I, Número1. (Barranquilla: febrero 15 de 1955), Cámara de Comercio de Barranquilla. 
Una capital fluvial que concentraba las principales sedes de las más importantes empresas navieras que se movían por el río. Eran muchos los intereses creados alrededor del transporte fluvial, y los empresarios de ese transporte presionaban al Gobierno y a sus organizaciones para que no se abandonara la ruta del río. En un editorial del Boletín de la Cámara de Comercio de Barranquilla del año 1959 se menciona la crisis ya visible del transporte por el Magdalena. El editorialista se quejaba de la posición de quienes pensaban que no era conveniente hacer nuevos gastos en el río "por cuanto el ferrocarril y las carreteras podrían sustituirlo con ventaja como medio de transporte". El editorial sostenía que era un craso error darle la espalda a una arteria que nos había regalado la naturaleza y que representaba un medio más económico para transportar la carga. Además, argumentaba que el país debía pensar en todas las vías de comunicación y por eso debía preservar todas las que se tienen. Por último, solicitaba invertir más en el mantenimiento del río, "así como se invierten habitualmente sumas cuantiosas para mantener y preservar carreteras y vías férreas". El tiempo se encargó de dejar a un lado este tipo de peticiones, que trataban de defender la navegación por el río y los intereses del empresariado de Barranquilla, principal damnificado con la crisis de la navegación a vapor ${ }^{21}$.

El complejo entramado que integró a Barranquilla con el interior a través del río se formó desde la segunda mitad del siglo XIX, cuando la urbe se convierte en el primer puerto para el comercio exterior colombiano, y no desapareció de inmediato después de la construcción del Terminal Marítimo. Esa red de transportes arrancaba en Puerto Colombia y se extendía hasta más allá del Magdalena medio, expandiéndose por tierra y por algunos cortos ferrocarriles por varios departamentos del interior a lado y lado del Gran río. El centro más dinámico de todo el conjunto era el viejo puerto fluvial de la ciudad, ubicado sobre los caños, mas no en la propia ribera del Magdalena ${ }^{22}$. Ese entramado de comercio y transportes se mantuvo por varias

21 B.C.C.B., Año V, Número 147. (Barranquilla: marzo 9 de 1959), p.1, Cámara de Comercio de Barranquilla. A pesar de las dificultades, el transporte de carga por el río Magdalena no desapareció enseguida sino que se transformó. Hacia el año 1955, la capacidad transportadora de los buques a vapor había caído al $12.4 \%$ en comparación con el $87.6 \%$ de los remolcadores diésel. El transporte de carga se transformó para enfrentar las exigencias de la competencia creciente de otras rutas y medios. B.C.C.B., Año II, Número 24. (Barranquilla: febrero 1 de 1956), p.4, Cámara de Comercio de Barranquilla.

22 Sobre el problema de las conexiones de Barranquilla y de la formación de su primer gran puerto fluvial, véase Milton Zambrano Pérez, El Puerto Fluvial de Barranquilla. En: Historia Empresarial de Barranquilla (1880-1980), Vol. 1. (Barranquilla: Ediciones Uninorte, 2014), 77 y siguientes. 
La construcción del nuevo Terminal Marítimo y Fluvial de Barranquilla ${ }^{24}$ fue un aliciente para seguir exportando e importando por la ciudad. Pero lo definitivo para que continuara el comercio exterior por Barranquilla, fue el mercado interior que se creó alrededor del río, el cual no desapareció como consecuencia de la pérdida del liderazgo portuario sino que se mantuvo por varias décadas más, sufriendo algunas transformaciones. Por ejemplo, en los años 50 y 60 los tradicionales barcos a vapor fueron reemplazados por vehículos más rápidos y con más capacidad de carga, movidos por motores que usaron diesel o gasolina. Los convoyes de planchones y remolcadores se convirtieron en los mejores medios para trasladar el ganado en pie, las maderas o el petróleo que continuaban saliendo por el Magdalena. Así mismo, para transportar las importaciones que iban hacia otros sitios de la Costa 0 del interior ${ }^{25}$.

La muerte del río como principal arteria para el comercio exterior colombiano no fue tan rápida como a menudo se $\mathrm{cree}^{26}$. Esa muerte no estaba relacionada solamente

23 A finales de los años 50, los líderes empresariales todavía expresaban en sus análisis la integración de Barranquilla con sus zonas de influencia desde el punto de vista comercial, industrial y en el esquema de transportes. En 1958, Raimundo Sojo Zambrano, exsecretario de la Cámara de Comercio de Barranquilla y a la sazón Gerente de la ANDI Seccional, sostenía que la ciudad era un centro de producción industrial y de distribución comercial que se vería favorecido con el aumento de la capacidad de consumo de su esfera de influencia. Para él, la esfera de influencia de la urbe no era solo la Costa Atlántica sino el oriente colombiano y hasta el centro y el occidente del país. B.C.C.B., Año III, Número 91. (Barranquilla: enero 13 de 1958), pp.3-6, Cámara de Comercio de Barranquilla.

24 El movimiento de carga y pasajeros por el río Magdalena no desapareció con el traslado del puerto principal a las instalaciones del nuevo Terminal. Entre 1940 y 1959 se movió por el puerto un promedio de 400.000 toneladas de carga; en el primer año se transportaron 166.472 toneladas y en el último del período, 482.067 toneladas. En el año 1954 se despachó el tonelaje más alto (681.330 toneladas) y el más bajo corresponde al año 1940. Los pasajeros embarcados en todo el período fueron, en promedio, unos 60.000 , siendo la cantidad más baja movilizada la de 1941 (42.357 pasajeros) y la más alta, en 1949 (70.737 pasajeros). Al final del período, en 1959, se movieron por el río 51.630 pasajeros, lo que demuestra que el transporte de pasajeros aún no moría en ese año. Adolfo Meisel Roca, Series Estadísticas..., p.39.

25 Entre los años 40 y 50, la Naviera Fluvial Colombiana era la empresa más importante de cuantas movían pasajeros por el río. El $80 \%$ de estos usaban los vapores de esa compañía para viajar entre el interior y la Costa. En los 40 y a principios de los 50, la Naviera empleaba unos diez barcos a vapor para el tráfico de pasajeros, aparte de poseer otros buques para carga 0 mixtos. Hacia los años 40, aparecieron nuevas empresas dedicadas al transporte de carga. La Compañía de Transportes Fluviales Magdalena Limitada, transportaba carga utilizando remolcadores diesel de hélice sumergida, con los cuales manejaba una capacidad de carga de unas 15.000 toneladas. Poseía también botes y botes-tanques para transportar carga sólida y líquida, con una capacidad de carga de 87.000 toneladas. Hacia el año 1933 se fundó en Barranquilla la Transportadora de Ganado S.A., primera empresa especializada en el transporte de ganado en pie por el Magdalena. Contaba con barcos y planchones adecuados para ese tipo de transporte. Gabriel Poveda Ramos, Vapores Fluviales en Colombia..., 460. Los intereses creados alrededor del comercio y de las empresas de transporte, permiten explicar también el mantenimiento de una regularidad económica dentro y alrededor del río que no murió de inmediato, sino muy lentamente.

26 De hecho, hacia finales de los años 60 del siglo XX, el movimiento de carga fluvial por el Terminal y los muelles privados alcanzó las 448.268 toneladas, de las cuales la fluvial local de llegada (o entrada) fue la más impor- 
con el ascenso de Buenaventura al rol de primer puerto, sino con la construcción de una nueva infraestructura de transportes ligada a las carreteras, a los puertos aéreos ${ }^{27}$, a los buses, a los camiones y a los aviones ${ }^{28}$. $Y$ esa nueva infraestructura tampoco surgió repentinamente sino poco a poco, obedeciendo a las limitaciones económicas del país.

El declive lento y definitivo de la navegación por el Magdalena mediante naves a vapor con rueda trasera empezó observarse sobre todo a finales de los años 50 del siglo XX. Entre los factores que contribuyeron a ese declive estuvieron el desarrollo de las carreteras, la competencia de los aviones, el uso de los camiones de carga, el Ferrocarril del Atlántico, los elevados costos laborales, las huelgas, el alto costo del funcionamiento de las naves a vapor, la dificultosa navegabilidad en el propio río, los elevados costos de mantenimiento de los puertos y el desinterés del Gobierno en la navegación por el Magdalena, entre otras razones. Es decir, se trató de un proceso muy complejo que no puede ser reducido a la simple pérdida del liderazgo portuario de la ciudad de Barranquilla.

Pero todavía en 1954, y siguiendo los datos del Informe Lebret, Barranquilla ocupaba el primer lugar en el movimiento de carga entre todos los puertos del Magdalena, con 275 toneladas descargadas ese año y 627 despachadas. Le seguían en carga despa-

tante, con 263.295 toneladas; la local de salida fue de 118.258 toneladas, en tanto que la marítima salida por vía fluvial fue de 64.577 y la de llegada de 2.139 toneladas. El volumen de carga fluvial de Barranquilla fue del $88,1 \%$ del total que se movió en el año 1966 por los puertos de Cartagena y Barranquilla, el cual fue en conjunto de 508.209 toneladas. José Consuegra Higgins, Importancia y necesidad de la conexión del Puerto Marítimo de Barranquilla con el Ferrocarril del Magdalena por el sistema fluvial-férreo. (Barranquilla: Empresa Puertos de Colombia, 1967), 35.

27 El transporte aéreo fue un medio secundario que se utilizó en Barranquilla desde las primeras décadas del siglo $X X$, inicialmente para mover pasajeros, correo o carga liviana. Casi a mediados de este siglo, entraron en escena los aviones de carga, que se convirtieron en un instrumento adicional para mover productos entre la urbe y el interior. En cuanto al movimiento de carga por vía aérea, en el año 1960 se embarcaron por el aeropuerto de la ciudad 18.010 toneladas métricas, que representaron el $76 \%$ del total de la carga transportada por esta vía por los aeropuertos del Caribe. La carga desembarcada ascendió en 1960 a 14.902 toneladas métricas, cifra que no varió mucho en 1966 (14.802 toneladas métricas). Op. cit., p.38. Los datos aportados aquí sirven para ilustrar la manera como la economía de la ciudad se fue reacomodando de acuerdo con los cambios que se presentaron en la infraestructura de transportes, en las vías y medios para desarrollar el comercio. En los 40, 50 y 60 el puerto de Barranquilla no cayó en un estancamiento y, por el contrario, se abrió a las nuevas alternativas que le entregaba el desarrollo del país. No está de más anotar que, a pesar del ascenso de Buenaventura, nunca dejó de ser un puerto importante para el comercio exterior y tampoco perdió su rol de primer puerto para ese comercio en el Caribe colombiano en las décadas mencionadas.

28 No deja de sorprender que hacia el año 1955 Barranquilla fuera reconocida como el primer puerto aéreo internacional del país, en cuanto al número de pasajeros y al volumen de carga de importación y exportación. Según datos del Boletín Mensual de Estadística número 46, que reflejan su movimiento en los 10 primeros meses de 1954, por Barranquilla entraron o salieron 29.851 pasajeros en ese lapso de tiempo, en tanto que por Bogotá solo lo hicieron 22.555, por Cali 12.991, y por Medellín 6.645. En cuanto a la carga importada o exportada, por la ciudad se movió 1.322.370.370 kilos, por Bogotá 1.059.090 kilos, por Medellín 872.013 y por Cali 392.772 kilos. B.C.C.B., Año I, Número 2. (Barranquilla: marzo 1 de 1955), p.3, Cámara de Comercio de Barranquilla. 
chada y descargada (que salía y entraba en departamentos del interior) Puerto Berrío, La Dorada y Puerto Salgar ${ }^{29}$. Las inercias infraestructurales, el lento desarrollo de medios y vías alternas de transporte y la falta de recursos del Estado, aparte de los intereses creados alrededor de los negocios fluviales y de comercio, le permitieron vivir a este sistema mucho más allá del principio del ascenso de Buenaventura.

La disminución o desaparición de las actividades relacionadas con el comercio por el río Magdalena no decayeron sin resistencia. El juego de intereses integrados a los transportes, las necesidades de la gente influida por el río y el lento desarrollo de la infraestructura de reemplazo a nivel nacional, alimentaban esa resistencia. Esto es lo que permite explicar la permanencia de ciertos medios y la aparición de otros nuevos. Entre 1945 y 1950, aún dominaban el tráfico por el río los barcos a vapor ${ }^{30}$. Pero ya operaban varios barcos remolcadores de motor diesel con hélices propulsoras. En el Magdalena y otros ríos, empezaron a aparecer lanchas con motor fuera de borda y con motor a gasolina a bordo. El hecho de que no existieran carreteras o ferrocarriles que unieran a Bogotá, Medellín o Bucaramanga con el litoral Caribe hacia los años 40 y antes de los 50 permitió que el río Magdalena siguiera cumpliendo su importante misión en el transporte de carga y pasajeros.

29 Otros puertos sobre el río fueron: Caracolí, Puerto Liévano, Gamarra, El Banco, Magangué y Calamar. A partir de todos los puertos se tejió una compleja urdimbre que integró a las zonas aledañas al Magdalena con las más lejanas, para mover carga y pasajeros desde sitios cercanos o remotos. De Castro Palacio, Arturo. Boletín Municipal de Estadística de Barranquilla, Vol. III, Número 17. (Barranquilla: septiembre 20 de 1934), p.26. Los puertos en el río para llegar a la ciudad de Ocaña, por ejemplo, eran Puerto Nacional y Bodega Ocaña. Para llegar hasta Bucaramanga, el desembarco era en Bodega Central. Puerto Berrío era el punto de entrada al departamento de Antioquia y a la ciudad de Medellín. Hacia Bogotá y Cundinamarca se seguía la ruta de Honda, desembarcando antes en Yeguas y tomando luego un ferrocarril hasta esta última ciudad. En todos los casos, el transporte era lento y muy difícil, combinando vías acuáticas alternas al río Magdalena, caminos para animales de carga y tiro y algunos cortos ferrocarriles. Era una odisea viajar desde y hacia el río, pero eso era lo que había, y todo se acomodó a ese delicado sistema. Martínez Aparicio, Antonio y Niebles A., Rafael. Directorio Anuario de Barranquilla, Año I. (Barranquilla: 1892), pp.32 y siguientes, Imprenta El Comercio. Como se había destacado, la compleja conexión creada alrededor del río Magdalena tenía sus antecedentes desde la época colonial, pero se desarrolló muchísimo desde la segunda mitad del siglo XIX, cuando el país impulsó el comercio exterior por el Magdalena. El café jugaría un papel decisivo en el desarrollo de ese comercio. Los datos del informe Lebret concuerdan con los de las fuentes locales en que se muestra que el transporte fluvial aún no está en crisis irreversible a mediados de los años 50 del siglo XX. En el Boletín de la Cámara se anota que a principios del año 1955 "la carga movilizada por el río Magdalena desde el puerto fluvial de Barranquilla, acusa un índice de expansión ligeramente notorio". En efecto, en el mes de febrero de ese año se movilizaron por el puerto fluvial 25.301.267 kilos, en tanto que en el mes de abril transitaron 38.163 .300 kilos. La comparación de los datos de abril de 1955 con los de abril de 1954 establece una diferencia favorable al año 1955 de 6.539 .076 kilos. Es decir, en el Boletín se sostiene que el transporte fluvial no solo no ha desaparecido sino que se expandió en el período considerado. B.C.C.B., Año I, Número 5. (Barranquilla: abril 15 de 1955), pp.2-3, Cámara de Comercio de Barranquilla.

30 En los años 50, la Naviera Colombiana S.A. movía carga y pasajeros por el Magdalena. Esta empresa, que tenía su sede principal en Barranquilla, contaba con oficinas en Medellín, Bogotá, La Dorada, Puerto Berrío, Barrancabermeja, El Banco y Magangué. El Economista, Año l, No 4. Barranquilla: marzo de 1955, p. 30. La red de transportes integraba el traslado por tierra o ferrocarril tanto para la carga como para los pasajeros. Un sistema tan firmemente asentado no desaparecería fácilmente. Véase: Alberto Mayor Mora, Francisco Javier Montoya y el inicio de las comunicaciones modernas en Colombia (Bogotá: Banco de la República-El Áncora Editores, 1999). 
Entre 1945 y 1957, la carga fue en aumento en tanto que el movimiento de pasajeros decrecía o se mantenía estacionario, en parte por la competencia del transporte aéreo. En 1945, por el río transitaron 1.210 .000 toneladas de carga y 217.483 pasajeros; en 1950, la carga ascendió a 1.593.000 toneladas, en tanto que el número de pasajeros bajó a 203.735. Hacia el año 1957 la carga movilizada fue de 2.016.000 toneladas, es decir, casi el doble de la movilizada en 1950 (Poveda-Ramos, 1998, pp.468-470). Este dato indica no un estancamiento sino un auge, al menos en el transporte de carga ${ }^{31}$.

Desde los comienzos de los años sesenta, se observa un cambio drástico en los medios de transporte usados en el río Magdalena. El tráfico de pasajeros cayó fuertemente, y solo transitaban el río unos 7 vapores de rueda. La carga se transportaba en unos 350 remolcadores de motor diesel y hélice sumergida, que poseían entre 60 y 1.800 caballos de fuerza. Así mismo, se movían 42 barcazas con capacidad de carga entre 1.000 y 5.000

toneladas, y unos 500 planchones y bongos para transportar carga líquida, a granel y general. La declinación relativa y la transformación del transporte fluvial, advino como consecuencia de la competencia de los buses, los camiones, los trenes y los aviones en el transporte de pasajeros y carga.

La construcción del Ferrocarril del Atlántico (concluido en 1961) le sustrajo pasajeros y carga a los buques a vapor, acelerando su desaparición como medio de transporte. Desde este año, no se construyó ningún vapor nuevo y los que quedaban fueron retirados en 1962 o 1963, convirtiéndose luego en chatarra en algún lugar del río. Los remolcadores diesel de 600 o 700 caballos de fuerza se hicieron cargo, a partir de esos tiempos, de la carga residual que aún se movía por el Magdalena (Román Bazurto, 2013, pp.66-67; Poveda-Ramos, 1998, pp.489-490; Acevedo Latorre, 1981).

Estos indicios históricos son muy útiles para aclarar que el descenso del comercio exterior por el río Magdalena fue un fenómeno bastante complejo y no tan rápido como algunos sugieren. Su explicación debe tener en cuenta las transformaciones infraestructurales que experimentó el país a partir, por lo menos, de los años 50

31 Según datos aportados por la Cepal, a mediados de los años 50 el Magdalena seguía siendo el río más importante del país en cuanto a navegación fluvial, captando el $95 \%$ del tráfico por los ríos de la nación, el cual aumentaba a comienzos de esa década por este río. El movimiento de carga y pasajeros no mostraba aún signos de decadencia. La carga movida en 1938 fue de 917 toneladas, en 1946 subió a 1.242 toneladas, en 1950 fue de 1.593 toneladas, en 1952 de 1.602 toneladas, y en 1954 de 1.775 toneladas. El ascenso también se vio en el transporte de pasajeros: 1938: 152.000; 1946: 218.000; 1950: 204.000; 1952: 222.000, y 1954: 283.000 pasajeros. Comisión Económica para la América Latina de las Naciones Unidas (Cepal). Análisis y proyecciones del desarrollo económico, III. El Desarrollo económico de Colombia (México: Naciones Unidas, 1957). 
del siglo XX. El ascenso portuario de Buenaventura por sí solo no permite explicar toda la complejidad del problema, debido al hecho de que el sistema de comercio y trasportes articulado alrededor del río podía seguir funcionando mucho tiempo más, al ser una salida expedita para el comercio exterior de regiones aisladas por geografía e infraestructura del sistema que se modeló alrededor de Buenaventura. La estocada definitiva al río provino de los cambios infraestructurales que no fueron motivados por la conversión de este puerto en el más importante del país, sino por las propias dificultades del Magdalena y por los adelantos en vías y medios que impusieron los tiempos.

El proceso de construcción de nuevas vías y de integración de nuevos medios solo se aceleró hacia los años 60 del siglo $X X_{1}^{32}$ aunque ya desde los años 50 había algunas carreteras $^{33}$. Entre tanto, la inercia del sistema de transportes y de comercio que tenía al río Magdalena como eje, sirvió de acicate para que Barranquilla continuara cumpliendo su rol de puerto para el comercio exterior de una parte importante del país que no podía conectarse con Buenaventura debido a la distancia o a la ausencia de ferrocarriles, carreteras u otros medios o vías ${ }^{34}$.

32 De acuerdo con datos del año 1966, la carga movilizada en camiones por el Terminal de Barranquilla fue de 349.852 toneladas, las cuales representaron el $59,4 \%$ del total de la carga movilizada por este medio de transporte en los tres puertos del Caribe. De esa cifra, entraron a la ciudad 32.686 toneladas y salieron hacia otras zonas del país 317.166 toneladas. José Consuegra Higgins, Importancia y necesidad de la conexión..., 36. Estos datos sirven para corroborar que el puerto mantuvo su funcionalidad ligada al comercio exterior y para mostrar que cuando la crisis del río Magdalena como medio de transporte empezó a pegar más fuerte, la ciudad se fue reacomodando a los nuevos medios y vías que se desarrollaron con las carreteras. El transporte aéreo también puso su grano de arena tanto en el transporte de carga como de pasajeros.

33 Hacia 1950 ya avanzaba la construcción de una carretera de Bogotá a Barranquilla y Santa Marta. A mediados de esa década se conectaron Medellín, Cartagena y Barranquilla por carretera. Esto permitió la entrada de los camiones, que duraban menos días viniendo del centro del país a la Costa, aunque el costo de la tonelada kilómetro por carretera fuese casi el doble de la tonelada-kilómetro fluvial. Desde 1956, el Ferrocarril del Atlántico unió a Bogotá con Medellín. En 1961, conectó a Santa Marta con estos dos importantes centros económicos. El ferrocarril era mucho más rápido que el transporte fluvial. En dos dias un cargamento llegaba hasta Bogotá o Medellín, mientras por el río duraba 10 o 15 días. Las tarifas ferroviarias eran iguales o menores que las del río, lo cual las hizo más competitivas. Gabriel Poveda Ramos, Vapores Fluviales..., 520. Las carreteras y el Ferrocarril sellaron la suerte definitiva de los transportes por el río. Pero ese efecto solo se vería en su plenitud a partir de los años 60.

34 Otro medio utilizado para mover carga de importación y exportación por Barranquilla fue el Ferrocarril de Santa Marta, conocido también como Ferrocarril del Atlántico. Este proceso empezó, sobre todo, desde principios de los años 60 del siglo XX. Hacia el año 1966, la carga transportada por ferrocarril que llegó a Barranquilla fue de 137 toneladas diarias, aproximadamente; y la que salió fue de 70 toneladas diarias. La carga enviada desde Barranquilla al Ferrocarril de Santa Marta en 1963 fue de 20.000 toneladas, cifra que se elevó a las 49.000 toneladas en 1966, lo que muestra un incremento del $145 \%$. Op. cit., pp.37-38. Estos datos son importantes porque sirven para ilustrar el hecho de que ni los empresarios ni las autoridades se cruzaron de brazos ante los problemas que se derivaban de la crisis del transporte por el río Magdalena, de la competencia de otros puertos por la carga o de los cambios inevitables en la infraestructura de transportes. 
Este hecho nacional permite explicar por qué Barranquilla no perdió su rol portuario en términos de comercio exterior ${ }^{35}$. Además, el puerto colombiano que más provecho socioeconómico le sacó a su función portuaria fue esta urbe, por lo cual dejó de ser un simple puerto de tránsito (como Buenaventura, por ejemplo) para las exportaciones e importaciones, al servir de nicho para muchas importaciones requeridas por sus empresas y al exportar al mercado mundial sus productos industriales.

Estas son las evidencias que facilitan explicar el complejo mundo de comercio y transportes en el cual, se insertó Barranquilla desde finales del siglo XIX. Un mundo económico y geográfico que también permite explicar los nexos que estableció la ciudad con un entorno que trascendió a la Región Caribe. Un entorno y unos nexos que son claves para comprender por qué el comercio exterior por el río Magdalena no se vino al suelo de inmediato, a pesar del ascenso portuario de Buenaventura. Y que también, ayudan a explicar por qué la urbe no detuvo su crecimiento económico, urbano y poblacional.

\section{Conclusiones}

Los datos históricos insertados en este estudio facilitaron la tarea de refutación de los principales supuestos y conclusiones del ensayo ¿Por qué se disipó el dinamismo industrial de Barranquilla?, publicado por Adolfo Meisel Roca a finales de los años 80 del siglo XX.

Este escrito, pionero dentro de la historiografía barranquillera, ha sido fundamental en la creación de unas ideas históricas sobre la urbe relacionadas con los años 40 y 50 del siglo Xx. Tanto los historiadores como los no historiadores repitieron el contenido del ensayo de Meisel Roca, aduciendo que a mediados de este siglo la urbe cayó en una especie de marasmo económico y social provocado por la pérdida

35 Ese rol portuario para el comercio exterior a través del río fue languideciendo lentamente. A principios de los años 50 del siglo XX, todavía no se mostraba muy claramente esa decadencia, si nos atenemos al movimiento de carga y pasajeros por el río Magdalena. En 1949, los barcos fluviales transportaron 1.287.000 toneladas de carga, cifra que subió en 1956 a 2.070.000 toneladas. En 1951, navegaban por el río 128 barcos, entre vapores y remolcadores diesel, con capacidad para transportar 49.000 toneladas de carga. Varios de los vapores para pasajeros aún ofrecían buenas condiciones y muchas comodidades para los viajeros. La mayoría de estos vapores contaban con aire acondicionado, sobre todo para quienes viajaban en plan turístico. Cabe destacar que en 1954 se embarcaron 283.400 pasajeros, una cifra todavía muy notable teniendo en cuenta los promedios históricos. Enrique Román Bazurto, Las Quillas de Barranquilla y su contribución al desarrollo..., 66. 
del liderazgo portuario a manos de Buenaventura, fenómeno ocurrido a finales de los años 30 de aquel siglo.

Meisel Rocal construyó sus asertos apoyándose en muy poca información factual, y utilizando la deducción lógica y la comparación histórica como principales herramientas de análisis. Su deducción básica fue esta: como Barranquilla surgió como centro económico y demográfico gracias a su función como puerto desde finales del siglo XIX, cualquier dificultad o reducción de esta función repercutiría negativamente sobre la economía y la sociedad barranquilleras.

De la pérdida del liderazgo portuario de la ciudad a manos de Buenaventura, Meisel Roca infirió un decaimiento industrial y poblacional; al conectar la economía citadina con el mercado regional "confirmó" que esta no había podido sostener su dinamismo de principios del siglo XX porque su mercado natural no se lo permitió, ya que era muy estrecho y no podía ayudarle a sostener su ritmo de crecimiento industrial. A partir de aquí, concluyó no solo que Barranquilla había perdido su liderazgo portuario a manos de Buenaventura (lo cual es innegable), sino que esa pérdida había provocado un estancamiento que se expresaba a nivel económico y poblacional.

El autor reforzó su hallazgo comparando las cifras de crecimiento poblacional de la ciudad con las de Bogotá, Medellín y Cali de comienzos de los años cincuenta, y sustentó su tesis de la pérdida del dinamismo en el empleo industrial, haciendo una extrapolación inadecuada de las cifras del empleo industrial de la rama textil con la del conjunto del empleo en toda la industria de Barranquilla.

El ensayo de Meisel Roca fue muy importante dentro de la historiografía local. Podría decirse que introdujo la idea del estancamiento y hasta de la crisis de la ciudad hacia los años 40 y 50 del siglo XX, como consecuencia de la pérdida del liderazgo portuario a manos de Buenaventura. Por estas razones, y por la secuela que aún produce entre los historiadores y los no historiadores, era necesario someterlo a una revisión crítica para resaltar sus debilidades y fortalezas, pero, sobre todo, por el hecho de que es un trabajo que contiene muchas imprecisiones y errores, que son el resultado de la escasez de material factual empleado para corroborar los asertos construidos. 
La crítica histórica apoyada en una mayor cantidad de indicios permite llegar a las siguientes conclusiones:

a. No es cierto que la pérdida del liderazgo portuario a finales de los años 30 del siglo $\mathrm{XX}$, se convirtió en la principal causa del estancamiento industrial de la urbe hacia los años 40 y 50 de aquel siglo. Las cifras históricas permitieron demostrar que la ciudad continuó su crecimiento en el plano industrial, en su empleo industrial, sin sufrir un daño irreparable por efecto de la supuesta decadencia portuaria.

b. La urbe tampoco decayó a nivel poblacional en los años 40 y 50 de ese siglo. El análisis de las cifras históricas de crecimiento poblacional permite comprobar que Barranquilla, en esas décadas, creció bien y que la pérdida del liderazgo portuario tampoco afectó ese crecimiento. En el año 1951, la ciudad exhibió la mayor tasa de crecimiento de población de todo el siglo XX, la cual está muy por encima de las tasas de las primeras décadas de este siglo. Una tasa de crecimiento del 4,7\%, como la que se dio en el año 1951, nunca es sinónimo de estancamiento, aunque esté por debajo de las de otras ciudades del país. El método comparativo no servía aquí para corroborar el estancamiento poblacional de Barranquilla, sino el análisis de las cifras históricas de la urbe. Estas cifras sirven para comprobar que Barranquilla crecía bien en el concierto regional y nacional y que no estaba estancada, como se infiere de una de las conclusiones del ensayo de Meisel Roca.

c. La explicación de la baja del dinamismo industrial como consecuencia de la pérdida del liderazgo portuario, se queda corta si no se revisan las cifras históricas de crecimiento industrial de la urbe. La revisión de las cifras de crecimiento industrial de Barranquilla hacia los años 40 y 50 del siglo XX, no nos indican una economía estancada o en crisis sino una economía en expansión, a pesar de todas las dificultades en el transporte por el río, como lo habían destacado los observadores de la época, en contra de lo que opina Meisel Roca en su ensayo.

d. Si la industria no estuvo estancada en esas décadas, tampoco resulta lógico preguntarse por qué se estancó y relacionar la respuesta con un hinterland que no ayudó a Barranquilla a seguir creciendo. El hecho es 
que la ciudad creció industrialmente a pesar de los problemas portuarios. ¿Por qué siguió creciendo, a pesar de lo que supone Meisel Roca? Porque la economía que giraba alrededor del río, no se vino al suelo a raíz de la pérdida del liderazgo portuario y porque el mercado de Barranquilla no estaba solo en la Región Caribe sino en todos los departamentos que se conectaron al sistema del río para desarrollar su comercio exterior 0 para hacer economía.

Al ensayo del colega Meisel Roca, le faltó una base factual más nutrida y un mejor conocimiento histórico de la esfera de influencia de Barranquilla en los tiempos que cumplía su rol de principal puerto para el comercio exterior del país. Cuando Buenaventura accedió al primer lugar en las exportaciones de café, a finales de los años 30 del siglo XX, la ciudad siguió cumpliendo su papel para su zona de influencia, y el sistema de transportes y de comercio de esa zona le ayudó a mantener un crecimiento aceptable para no caer en el estancamiento que muestra Meisel Roca en su ensayo. A este fenómeno contribuyó también la propia demanda interna de la urbe y la demanda externa que tampoco se detuvo.

En consecuencia, es necesario revaluar los supuestos y conclusiones sobre la ciudad en los años 40 y 50 . No se puede demostrar, con las cifras de la época, que la urbe decayó o que entró en un estancamiento general. Tampoco es posible sostener, basándonos en el análisis histórico, que el efecto inmediato de la pérdida del liderazgo portuario de finales de los años 30, condujo a la pérdida del dinamismo industrial que colocó en una coyuntura de depresión a la economía, a la población y al conjunto de la sociedad barranquillera.

\section{Referencias Bibliográficas}

\section{Fuentes primarias}

Archivo Histórico del Atlántico. (s.f.a). Boletín Municipal de Estadística, III(17). Barranquilla, Colombia: Archivo Histórico del Atlántico.

Archivo Histórico del Atlántico. (s.f.b). Boletín Municipal de Estadística, III(19). Barranquilla, Colombia: Archivo Histórico del Atlántico.

B.C.C.B., (1955, junio, 1). I(8). Barranquilla: Cámara de Comercio de Barranquilla. 
Cámara de Comercio de Barranquilla (C.C.B.). (1955a, febrero 15). Boletín Comercial, (1). Barranquilla, Colombia: C.C.B.

Cámara de Comercio de Barranquilla (C.C.B.). (1955b, marzo 1ro). Boletín Comercial, (2). Barranquilla, Colombia: C.C.B.

Cámara de Comercio de Barranquilla (C.C.B.). (1955c, abril 15). Boletín Comercial, I(5). Barranquilla, Colombia: C.C.B.

Cámara de Comercio de Barranquilla (C.C.B.). (1955d, mayo 10). Boletín Comercial, I(6). Barranquilla, Colombia: C.C.B.

Cámara de Comercio de Barranquilla (C.C.B.). (1955e, mayo 15). Boletín Comercial, I(7). Barranquilla, Colombia: C.C.B.

Cámara de Comercio de Barranquilla (C.C.B.). (1955f, junio 1ro). Boletín Comercial, I(8). Barranquilla, Colombia: C.C.B.

Cámara de Comercio de Barranquilla (C.C.B.). (1955g, noviembre 1ro). Boletín Comercial, I(18). Barranquilla, Colombia: C.C.B.

Cámara de Comercio de Barranquilla (C.C.B.). (1956, febrero 1ro). Boletín Comercial, II(24). Barranquilla, Colombia: C.C.B.

Cámara de Comercio de Barranquilla (C.C.B.). (1958, enero 13). Boletín Comercial, III(91). Barranquilla, Colombia: C.C.B.

Cámara de Comercio de Barranquilla(C.C.B.).(1958, septiembre 15). Boletín Comercial, VI(125). Barranquilla, Colombia: C.C.B.

Cámara de Comercio de Barranquilla (C.C.B.). (1959a, marzo 9). Boletín Comercial, V(147). Barranquilla, Colombia: C.C.B.

Cámara de Comercio de Barranquilla (C.C.B.). (1959b, mayo 4). Boletín Comercial, V(155). Barranquilla, Colombia: C.C.B.

Cámara de Comercio de Barranquilla (C.C.B.). (1959c, agosto 3). Boletín Semanal, V(168). Barranquilla, Colombia: C.C.B.

Contraloría General de la República. (1947). Primer Censo Industrial de Colombia, Atlántico. Bogotá, Colombia: Contraloría General de la República.

El Economista. (1955, marzo). El Economista, I(4). Barranquilla, Colombia.

Gómez Picón, R. (1983). Magdalena, río de Colombia. Bogotá: Tercer Mundo.

Lebret, J. L. (1958). Estudio sobre las condiciones del desarrollo de Colombia. Bogotá: Cromos. 
Martínez-Aparicio, A. y Niebles, R. (1892). Directorio Anuario de Barranquilla, (I). Barranquilla, Colombia: Imprenta El Comercio.

Meisel Roca, A. (1993). “¿Por qué se disipó el dinamismo industrial de Barranquilla?" En: ¿Por qué se disipó el dinamismo industrial de Barranquilla? Y otros ensayos de historia económica de la Costa Caribe, eds. A. Meisel Roca y E. Posada Carbó. Barranquilla: Ediciones Gobernación del Atlántico-Editorial Presencia.

Poveda Ramos, G. (1988). Vapores Fluviales en Colombia. Bogotá: TM Editores - Colciencias.

Primer Censo Industrial de Colombia, Atlántico. (1947). Bogotá: Contraloría General de la República.

\section{Fuentes secundarias}

Acevedo-Latorre, E. (1981). El Río Grande de la Magdalena. Apuntes sobre su historia, su geografía y sus problemas. Bogotá, Colombia: Banco de la República.

Camacho-Roldán, S. (1973). Notas de viaje: Colombia y Estados Unidos de América (tomo I). Bogotá, Colombia: Talleres Gráficos del Banco de la República.

Consuegra-Higgins, J. (1967). Importancia y necesidad de la conexión del puerto marítimo de Barranquilla con el ferrocarril del Magdalena por el sistema fluvialférreo. Barranquilla, Colombia: Empresa Puertos de Colombia.

Gómez-Picón, R. (1983). Magdalena, río de Colombia. Bogotá, Colombia: Tercer Mundo.

Lebret, J. L. (1958). Estudio sobre las condiciones del desarrollo de Colombia. Bogotá, Colombia: Cromos.

Mayor-Mora, A. (1999). Francisco Javier Montoya y el inicio de las comunicaciones modernas en Colombia. Bogotá: Banco de la República, El Áncora Editores.

Meisel-Roca, A. (1987). ¿Por qué se disipó el dinamismo industrial de Barranquilla? Lecturas de Economía, (23), 57-84.

Meisel-Roca, A., y otros (1991). Series estadísticas de Barranquilla. Barranquilla, Colombia: Banco de la República, Subgerencia Técnica.

Meisel-Roca, A. \& Posada-Carbó, E. (1993). ¿Por qué se disipó el dinamismo industrial de Barranquilla? Y otros ensayos de historia económica de la costa Caribe. Barranquilla, Colombia: Gobernación del Atlántico, Editorial Presencia.

Naciones Unidas - CEPAL (1957). El Desarrollo Económico de Colombia, Análisis y Proyecciones del Desarrollo Económico (tomo III). México: Naciones Unidas. 
Nichols, T. E.(1973). Tres puertos de Colombia. Estudio sobre el desarrollo de Cartagena, Santa Marta y Barranquilla. Bogotá, Colombia: Banco Popular.

Noguera-Mendoza, A. (1980). Crónica grande del río de la Magdalena (tomos I y II). Bogotá, Colombia: Ediciones Sol y Luna.

Posada-Carbó, E. (1984). Una invitación a la historia de Barranquilla. Bogotá, Colombia: Cámara de Comercio de Barranquilla, CEREC.

Posada-Carbó, E. (1988). El Caribe colombiano, una historia regional (1870-1950). Bogotá, Colombia: Banco de la República, El Áncora Editores.

Poveda-Ramos, G. (1998). Vapores fluviales en Colombia. Bogotá, Colombia: TM Editores, Colciencias.

Román-Bazurto, E. (2013). Las quillas de Barranquilla y su contribución al desarrollo marítimo y fluvial del país. Bogotá, Colombia: Armada Nacional de Colombia.

Zambrano-Pérez, M. (1998). El desarrollo del empresariado en Barranquilla, 1880-1945. Barranquilla, Colombia: Fondo de Publicaciones de la Universidad del Atlántico.

Zambrano-Pérez, M. (2014). El puerto fluvial de Barranquilla. Historia Empresarial de Barranquilla (1880-1980)(tomo 1). Barranquilla, Colombia: Ediciones Uninorte. 